\title{
Novel Assays to Distinguish Between Properdin-Dependent and Properdin-Independent C3 Nephritic Factors Provide Insight Into Properdin-Inhibiting Therapy
}

\section{OPEN ACCESS}

Edited by:

Peter F. Zipfel,

Leibniz Institute for Natural Product

Research and Infection

Biology, Germany

Reviewed by:

Bo Nilsson,

Uppsala University, Sweden Marina Vivarelli, Bambino Gesù Ospedale Pediatrico,

*Correspondence: Lambertus P. W. J. van den Heuvel bert.vandenheuvel@radboudumc.nl

tThese authors have contributed equally to this work

Specialty section: This article was submitted to

Molecular Innate Immunity,

a section of the journal

Frontiers in Immunology

Received: 30 November 2018 Accepted: 28 May 2019

Published: 17 June 2019

Citation:

Michels MAHM, van de Kar NCAJ, van den Bos RM, van der Velden TJAM, van Kraaij SAW, Sarlea SA, Gracchi V, Oosterveld MJS, Volokhina EB and van den Heuvel LPWJ (2019) Novel

Assays to Distinguish Between

Properdin-Dependent and

Properdin-Independent C3 Nephritic

Factors Provide Insight Into

Properdin-Inhibiting Therapy.

Front. Immunol. 10:1350

doi: 10.3389/fimmu.2019.01350

\begin{abstract}
Marloes A. H. M. Michels ${ }^{1}$, Nicole C. A. J. van de Kar ${ }^{2}$, Ramon M. van den Bos ${ }^{3}$, Thea J. A. M. van der Velden ${ }^{2}$, Sanne A. W. van Kraaij ${ }^{4}$, Sebastian A. Sarlea ${ }^{2}$, Valentina Gracchi ${ }^{5}$, Michiel J. S. Oosterveld ${ }^{6}$, Elena B. Volokhina ${ }^{2,4 t}$ and Lambertus P. W. J. van den Heuvel ${ }^{2,4,7 * t}$ on behalf of the COMBAT Consortium

1 Department of Pediatric Nephrology, Radboud University Medical Center, Radboud Institute for Molecular Life Sciences, Amalia Children's Hospital, Nijmegen, Netherlands, ${ }^{2}$ Department of Pediatric Nephrology, Radboud University Medical Center, Amalia Children's Hospital, Nijmegen, Netherlands, ${ }^{3}$ Crystal and Structural Chemistry, Bijvoet Center for Biomolecular Research, Department of Chemistry, Faculty of Science, Utrecht University, Utrecht, Netherlands, ${ }^{4}$ Department of Laboratory Medicine, Radboud University Medical Center, Nijmegen, Netherlands, ${ }^{5}$ Department of Pediatric Nephrology, University Medical Center Groningen, University of Groningen, Groningen, Netherlands, ${ }^{6}$ Department of Pediatric Nephrology, Emma Children's Hospital, Amsterdam University Medical Center, Amsterdam, Netherlands, ${ }^{7}$ Department of Pediatrics/Pediatric Nephrology and Department of Development and Regeneration, University Hospitals Leuven, Leuven, Belgium
\end{abstract}

C3 glomerulopathy (C3G) is an umbrella classification for severe renal diseases characterized by predominant staining for complement component $\mathrm{C} 3$ in the glomeruli. The disease is caused by a dysregulation of the alternative pathway (AP) of the complement system. In more than half of C3G patients C3 nephritic factors (C3NeFs) are found. These autoantibodies bind to the AP C3 convertase, prolonging its activity. C3NeFs can be dependent or independent of the complement regulator properdin for their convertase-stabilizing function. However, studies to determine the properdin-dependency of $\mathrm{C} 3 \mathrm{NeFs}$ are rare and not part of routine patient workup. Until recently, only supportive treatments for C3G were available. Complement-directed therapies are now being investigated. We hypothesized that patients with properdin-dependent C3NeFs may benefit from properdin-inhibiting therapy to normalize convertase activity. Therefore, in this study we validated two methods to distinguish between properdin-dependent and properdin-independent C3NeFs. These methods are hemolytic assays for measuring convertase activity and stability in absence of properdin. The first assay assesses convertase stabilization by patient immunoglobulins in properdin-depleted serum. The second assay measures convertase stabilization directly in patient serum supplemented with the properdin-blocking agent Salp20. Blood samples from 13 C3NeF-positive C3G patients were tested. Three patients were found to have properdin-dependent C3NeFs, whereas the $\mathrm{C} 3 \mathrm{NeF}$ activity of the other ten patients was independent of properdin. The convertase-stabilizing activity in the samples of the patients with properdin-dependent C3NeFs disappeared in absence of properdin. These data indicate that inhibition 
of properdin in patients with properdin-dependent C3NeFs can normalize convertase activity and could represent a novel therapy for normalizing AP hyperactivity. Our assays provide a tool for identifying C3G patients who may benefit from properdin-inhibiting therapy and can be incorporated into standard C3G laboratory investigations.

Keywords: complement system, glomerulopathy, therapy, Salp20

\section{INTRODUCTION}

C3 glomerulopathy (C3G) is a recently introduced classification for rare but severe renal diseases characterized by predominant deposition of complement component C3 in glomeruli $(1,2)$. C3G patients may present with a variety of symptoms, including glomerulonephritis with varying degrees of renal failure, hematuria, hypertension, proteinuria, nephrotic syndrome, and low serum C3. Prognosis is generally poor with a high risk of progression to end-stage renal diseases and a risk of recurrence in kidney transplants of $50 \%(3-10)$. Diagnosis of C3G is made when on kidney biopsy immunofluorescence staining for C3 is $\geq 2$ orders of magnitude higher than for immunoglobulins (Igs) $(2,11,12)$. Based on electron microscopy appearance, C3G can be subdivided into dense deposit disease (DDD) and C3 glomerulonephritis (C3GN). DDD is characterized by very dense band-like intramembranous deposits, whereas the deposits found in $\mathrm{C} 3 \mathrm{GN}$ are less dense and can show a more variable pattern $(2,12)$.

The complement system is part of innate immunity and clears pathogens and aberrant host cells from the body (13, 14). Complement can be activated via three pathways: the classical, lectin, and alternative pathway (AP). The complement depositions in C3G are the result of uncontrolled AP activity (12, 15). The AP is constantly active at a low rate by the spontaneous hydrolysis of $\mathrm{C} 3$ (tick-over), which allows a quick response to triggers. Hydrolyzed C3 $\left[\mathrm{C} 3\left(\mathrm{H}_{2} \mathrm{O}\right)\right]$ is functionally similar to $\mathrm{C} 3 \mathrm{~b}$ and able to form an initial $\mathrm{C} 3$ convertase after it reacts with Factor $B$ and Factor D. The resulting $\mathrm{C} 3\left(\mathrm{H}_{2} \mathrm{O}\right) \mathrm{Bb}$ complex cleaves small amounts of $\mathrm{C} 3$ into $\mathrm{C} 3 \mathrm{a}$ and $\mathrm{C} 3 \mathrm{~b}$. Once the system is triggered, an amplification loop leads to full activation of the complement cascade. C3b binds to cell surfaces with its reactive thioester to promote their phagocytosis in a process known as opsonization. Besides, bound C $3 \mathrm{~b}$ can form new C3 convertases ( $\mathrm{C} 3 \mathrm{bBb})$ that in turn convert more $\mathrm{C} 3$ into $\mathrm{C} 3 \mathrm{~b}$. When the $\mathrm{C} 3 \mathrm{~b}$ density on a surface becomes high enough, $\mathrm{C} 3 \mathrm{bBbC} 3 \mathrm{~b}$ complexes, better known as C5 convertases, can be formed (16). C5 convertases cleave C5 into its active fragments C5a and C5b, and hereby

\footnotetext{
Abbreviations: AP, Alternative pathway; C3G, C3 glomerulopathy; C3GN, C3 glomerulonephritis; $\mathrm{C} 3 \mathrm{NeF}(\mathrm{s}), \mathrm{C} 3$ nephritic factor(s); DDD, Dense deposit disease; EDTA, Ethylenediamine-tetraacetic acid; ELISA, Enzyme-linked immunosorbent assay; hi-NHS, Heat-inactivated pooled normal human serum; $\operatorname{Ig}(\mathrm{s})$, Immunoglobulin(s); FH, Factor H; FI, Factor I; IC-MPGN, Immune complex-mediated membranoproliferative glomerulonephritis; Mg-EGTA, Magnesium-ethylene glycol tetraacetic acid; NHP, Pooled normal human EDTAplasma; NHS, Pooled normal human serum; RbE, Rabbit erythrocyte; $t_{\max }$, (time point of) maximal convertase activity; $\triangle \mathrm{P}$-NHS, Properdin-depleted normal human serum; $\triangle \mathrm{C} 3$-NHS, C3-depleted normal human serum.
}

initiate terminal pathway activity. The end product is a poreforming, lytic C5b-9 complex, also known as the membrane attack complex.

In healthy individuals, the AP is strictly regulated. Circulating factors in blood, such as Factor H (FH) and Factor I (FI), and membrane-bound inhibitory proteins act together to protect from excessive AP activation and AP attack on healthy cells. Inhibitors of C3 convertase activity promote the decay of the convertase complex or act as cofactors for FI, which enzymatically inactivates $\mathrm{C} 3 \mathrm{~b}$ resulting in $\mathrm{C} 3 \mathrm{~b}$ breakdown fragments $(14,17)$. It is these $\mathrm{C} 3$ breakdown fragments that are typically found in the glomeruli of C3G patients (18). There is also a positive regulator that promotes instead of inhibits C3 convertase activity: properdin, a glycoprotein mainly synthesized by leukocytes $(19,20)$. Properdin stabilizes the C3bBb complex by forming C3bBbP, which enhances its half-life 5-10 fold (21). The exact function of properdin in the C5 convertase is not known yet (20).

When the sophisticated balance of complement activation and inhibition is disturbed, damage can occur to healthy host tissues. The glomeruli are thought to be especially vulnerable to overactive complement activity $(22,23)$. In patients with $\mathrm{C} 3 \mathrm{G}$, several pathogenic causes leading to an overactive AP can be found. Around $20 \%$ of patients has mutations in genes encoding for complement inhibitory proteins (loss-of-function mutations) or activating components (gain-of-function mutations) $(5,8,15)$. A more common finding in C3G patients are C3 nephritic factors (C3NeFs). These autoantibodies stabilize the C3 convertase complex and prolong its activity (24). In contrast to properdin, $\mathrm{C} 3 \mathrm{NeFs}$ are not part of normal human complement homeostasis. They are found in $\sim 40-50 \%$ of C3GN patients and in $\sim 80 \%$ of DDD patients $(5,8,25-27)$.

C3NeFs are functionally heterogeneous. The autoantibodies bind to neoepitopes on the $\mathrm{C} 3 \mathrm{bBb}(\mathrm{P})$ complex to inhibit the intrinsic, spontaneous and extrinsic, accelerated decay mediated by complement regulators to varying degrees (28-32). Besides, studies dating back to the late $80 \mathrm{~s} / 90 \mathrm{~s}$ have reported that $\mathrm{C} 3 \mathrm{NeFs}$ may be dependent or independent of properdin for their ability to stabilize convertases $(33,34)$. Several recent studies have confirmed the presence of these two types of $\mathrm{C} 3 \mathrm{NeF}(4,27,31)$.

At the moment, therapy for $\mathrm{C} 3 \mathrm{G}$ is mainly supportive and entails anti-proteinuric and immunosuppressive medication (10, 12). In recent times, the focus has shifted more and more toward targeting of the complement system (35). Eculizumab, a humanized anti-C5 antibody, was proven very efficacious in patients with atypical hemolytic uremic syndrome (36), which is also a renal disease strongly associated with uncontrolled AP 
activity. Nonetheless, C3G patients have shown an inconsistent response to this drug (37). Since the clinical features of C3G may derive predominantly from C3 activation, C3G patients may benefit from blocking $\mathrm{C} 3$ and/or C3 convertase activity (38). Therefore, there is increasing interest in inhibition of AP complement activation at an early phase, such as inhibiting C3, Factor B or Factor D $(35,39)$, or non-canonical targets such as renin, which also has recently been shown to have $\mathrm{C} 3$-cleaving capacities (40).

We hypothesized that C3G patients with properdindependent $\mathrm{C} 3 \mathrm{NeFs}$ might benefit from therapies targeting properdin, leading to normalization of $\mathrm{C} 3$ convertase activity. In this study, we established methods to distinguish between properdin-dependent and properdin-independent $\mathrm{C} 3 \mathrm{NeFs}$ and subsequently investigated whether convertase stabilization could be normalized by properdin inhibition in patients with properdin-dependent $\mathrm{C} 3 \mathrm{NeFs}$.

\section{MATERIALS AND METHODS}

\section{Human Serum and EDTA-Plasma Samples}

Serum and ethylenediamine-tetraacetic acid (EDTA)plasma samples were obtained from patients referred to the Radboudumc and from healthy controls. Exclusion criteria for healthy controls were fever, bacterial and/or viral infections in the preceding 2 weeks, chronic illness, inherited or acquired immune disorders, and immunosuppressive medication. The study was carried out in accordance with the recommendations of the appropriate version of the Declaration of Helsinki. Samples were processed according to protocol as previously described (41). For control material, pooled normal human serum (NHS) and pooled normal human EDTA-plasma (NHP) were produced from samples of 20 healthy volunteers. In addition, heat-inactivated NHS (hi-NHS) was prepared by incubating NHS for $30 \mathrm{~min}$. at $56^{\circ} \mathrm{C}$. Properdin-depleted ( $\triangle \mathrm{P}-\mathrm{NHS}$; A339) and C3-depleted normal human serum ( $\triangle \mathrm{C} 3$-NHS; A314) were purchased from Complement Technology (Tyler, TX, USA).

\section{Quantification of Complement Proteins and Activation Products}

Serum C3 levels were measured by nephelometry following the standardized diagnostic procedure of the Radboudumc using IMMAGE ${ }^{\circledR}$ Immunochemistry Systems (Beckman Coulter, Brea, CA, USA). Sandwich enzyme-linked immune sorbent assays (ELISAs) were used to quantify all other complement (regulatory) proteins. Except for the properdin ELISA, all protocols are currently operational in routine diagnostics at the Radboudumc. C5 levels were measured in human serum or EDTA-plasma using goat polyclonal antiserum to human C5 (A306; Quidel, San Diego, CA, USA), combined with a mouse monoclonal anti-human C5 antibody (A217; Quidel) for detection. FH and FI were quantified in serum or EDTA-plasma samples. FH was detected using a polyclonal goat anti-human FH antibody (A312; Quidel), followed by a mouse monoclonal antihuman FH antibody (A229; Quidel). FI was quantified using a polyclonal sheep anti-human FI antibody (LN1301932; LabNed, Amstelveen, the Netherlands) and subsequently detected using a mouse monoclonal anti-human FI antibody (OX-21; ProSci, Poway, CA, USA). Plate readout was similar for these assays, namely using polyclonal goat anti-mouse antibodies conjugated to horseradish peroxidase (P0447; Dako, Glostrup, Denmark) followed by the substrate o-phenylenediamine dihydrochloride. Results were calculated based on calibration lines produced by the commercially obtained purified human protein standards C5 (204888; Calbiochem), FH (341274; Calbiochem), and FI (A138, Complement Technology). The activation markers C3bBbP, C3bc, and C5b-9 were measured in EDTA-plasma by ELISA as previously described $(42,43)$. The ELISA for properdin detection in serum was set up and optimized based on previously described protocol (44). In brief, a mouse monoclonal antihuman properdin antibody (A233; Quidel) was used as the capture antibody and for detection a polyclonal rabbit antihuman properdin antibody labeled with digoxigenin (a kind gift of Prof. C. van Kooten, Leiden University Medical Center). After addition of an anti-digoxigenin antibody conjugated to horseradish peroxidase (Roche, Mannheim, Germany), the plate was developed with tetramethylbenzidine and results were calculated based on a calibration line produced by an NHS standard that was calibrated against the described serum standard (44).

\section{Salp20 Production and Purification}

A DNA fragment encoding Ixodes scapularis Salp20 [UniProtKB: Q95WZ1 (residue 22-183)] was amplified by PCR from Salp20 synthetic DNA optimized for mammalian expression (GeneART ThermoFisher), and ligated into BamHI-NotI sites of vector pUPE106.03 (U-Protein Express BV, Utrecht, the Netherlands). The expressed protein contained a cystatin secretion signal peptide, an N-terminal (His6)GlySer-tag and an C-terminal Ala3 cloning artifact due to the NotI restriction site. The construct was transiently expressed in $\mathrm{N}$-acetylglucosaminyltranferase Ideficient (GnTI-) Epstein-Barr virus nuclear antigen I(EBNA1)expressing HEK293 cells cultured in suspension (U-Protein Express BV, Utrecht, the Netherlands). Secreted Salp20 was captured by incubating culture medium with $\mathrm{Ni}$-Sepharose excel beads (GE Healthcare) at $4^{\circ} \mathrm{C}$ for $2 \mathrm{~h}$, followed by washing with $25 \mathrm{mM}$ HEPES pH 7.8, $500 \mathrm{mM} \mathrm{NaCl}, 15 \mathrm{mM}$ imidazole. After elution using the washing buffer supplemented with $250 \mathrm{mM}$ imidazole the sample was further purified by gel-filtration using a Superdex 200 increase 10/300 GL column (GE Healthcare) equilibrated in $25 \mathrm{mM}$ HEPES pH 7.8, $150 \mathrm{mM} \mathrm{NaCl}$. Salp20 was concentrated to $8.4 \mathrm{mg} / \mathrm{ml}$ by centrifugation using a $5-\mathrm{kDa}$ cutoff concentrator before plunge freezing in liquid nitrogen and storage at $-80^{\circ} \mathrm{C}$.

\section{Ig Purification}

Purified Ig fractions were obtained from the EDTA-plasma samples of patients P1 to P6 and from NHP as previously described (41). In short, Igs were isolated using a protein A/G affinity chromatography column (Thermo Fisher Scientific, Waltham, MA, USA). Ig fractions were subsequently dialyzed against phosphate buffered saline and concentrated to the original plasma sample volume using a concentrator with a $10 \mathrm{kDa}$ molecular weight cut-off. The Ig concentrations were 
measured using NanoDrop Spectrophotometer (Thermo Fisher Scientific) and yielded: $4.7 \mathrm{mg} / \mathrm{ml}$ (P1), $2.1 \mathrm{mg} / \mathrm{ml}$ (P2), 9.7 $\mathrm{mg} / \mathrm{ml}$ (P3), $10.2 \mathrm{mg} / \mathrm{ml}$ (P4), $8.6 \mathrm{mg} / \mathrm{ml}$ (P5), $12.5 \mathrm{mg} / \mathrm{ml}$ (P6), and $10.7 \mathrm{mg} / \mathrm{ml}$ (NHP). The Ig fractions were not contaminated with properdin as tested in the ELISA above.

\section{Convertase Activity Assays}

AP convertase activity assays are two-step hemolytic assays in which the assembly of convertases is separated from C5b-9 formation and hemolysis using a C5-blocking agent. These assays were performed according to a previously described protocol (41) but with adaptations in the first step of the assay for convertase assembly. Rabbit erythrocyte (RbE) working suspensions were prepared by washing the $\mathrm{RbE}$ in a magnesium-ethylene glycol tetraacetic acid (Mg-EGTA) buffer $(2.03 \mathrm{mM}$ veronal buffer, $\mathrm{pH}$ 7.4, $10 \mathrm{mM}$ EGTA, $7 \mathrm{mM} \mathrm{MgCl}_{2}, 0.083 \%$ gelatin, $115 \mathrm{mM} \mathrm{D}$ glucose, and $60 \mathrm{mM} \mathrm{NaCl}$ ) followed by calibration to standardize the number of erythrocytes in each experiment. In all assays, $10 \mu \mathrm{l}$ of prepared RbE were mixed with $20 \mu \mathrm{l}$ of $150 \mathrm{nM}$ of the C5 inhibitor eculizumab diluted in Mg-EGTA. Subsequently, at different time points $20 \mu \mathrm{l}$ of human test serum, i.e., NHS, $\triangle \mathrm{P}$-NHS, patient serum or $\triangle \mathrm{C} 3$-NHS, diluted in Mg-EGTA to a concentration of 9.5 or $12.5 \%$, was added for the convertase assembly at $37^{\circ} \mathrm{C}$. Alternatively, the test serum was supplemented with Ig fractions in a 1:1 (standard) or 1:3 volume ratio, or with purified properdin (A139, Complement Technology), Salp20, and/or C3 (A113, Complement Technology) to obtain final concentrations as indicated in figure legends. These protein concentrations are corrected for the used serum percentage, i.e., indicating the concentration per volume of undiluted serum. Patient sera were always tested mixed with an equal volume of NHS to compensate for possible low C3 levels (41). As a model for patient serum with low C3, $\triangle \mathrm{C} 3$-NHS was treated similarly. After convertase assembly in this first step, erythrocytes were washed with cold EDTA-gelatin veronal buffer (EDTA-GVB; $4.41 \mathrm{mM}$ veronal buffer, $0.1 \%$ gelatin, $130 \mathrm{mM} \mathrm{NaCl}, \mathrm{pH} 7.4$ ) to wash away excessive C5-inhibitor and unbound complement components. The second step of the assay, in which the recovered erythrocytes were overlaid with guinea pig serum diluted in EDTA-GVB as a source of C5b-9 components for generating hemolysis, was not subjected to any changes in this study. Hemolysis levels are given as percentage of full lysis of erythrocytes in water, and hi-NHS served as a negative control in all assays.

\section{RESULTS}

\section{Patient Characteristics and Complement Profiles}

For this study, 13 pediatric patients (age range 3-17 years) who were referred to the Radboudumc because of a (suspicion of) C3G diagnosis were selected based on a positive test for prolonged convertase activity, i.e., $\mathrm{C} 3 \mathrm{NeF}$ activity, in diagnostic settings (41), and based on the availability of sufficient and appropriate serum and plasma samples taken in the diagnostic phase (Table 1). Subdivision into C3GN or DDD was based on the renal pathology report following the guidelines described in the consensus report of the first C3G Meeting (2). One patient did not meet the $\mathrm{C} 3 \mathrm{G}$ criteria and was diagnosed with immune complex-mediated membranoproliferative glomerulonephritis (IC-MPGN). Genetic complement analysis and the analysis of complement parameters in serum/plasma were performed in all patients (Table 1). Complement activation markers and levels of complement (regulatory) proteins showed strong variations among patients. All samples taken for these complement investigations, including the testing for properdin dependency of $\mathrm{C} 3 \mathrm{NeF}$, were obtained during the initial diagnostic phase at presentation ( $\mathrm{P} 2, \mathrm{P} 4, \mathrm{P} 5, \mathrm{P} 6, \mathrm{P} 8, \mathrm{P} 9$, and $\mathrm{P} 11)$ or during a later stage of disease in which patient samples remained positive for $\mathrm{C} 3 \mathrm{NeF}$ activity (P1, P3, P7, P10, P12, and P13). Patients P1, P3, P7, P10, and P13 continued to show signs of ongoing complement activation, i.e., low serum C3 levels and elevated complement activation products, despite of normal renal function. Interestingly, the levels of C3, C5, and properdin of P12 were decreased at initial presentation (combined with elevated $\mathrm{C} 3 \mathrm{bBbP}$ and TCC), but the complement consumption and renal function normalized after 1 year. Data shown for this patient in Table 1 belong to this partial remission phase in which $\mathrm{C} 3 \mathrm{NeF}$ activity remained present, since not enough patient material from acute phase was available. Due to the absence of EDTA-plasma material from the acute phase of $\mathrm{P} 8$, the reported activation markers $\mathrm{C} 3 \mathrm{bBbP}, \mathrm{C} 3 \mathrm{bc}$, and TCC for this patient are from a later stage of disease in which there was ongoing C3 activation. Patient P2 developed end-stage renal disease within the first 3 months after presentation and received hemodialysis.

\section{Two Novel Methods to Distinguish Between Properdin-Dependent and Properdin-Independent C3NeFs}

We previously validated a hemolytic assay to monitor convertase activity over time in human serum. This method enabled the detection of factors causing increased convertase stability such as $\mathrm{C} 3 \mathrm{NeFs}$ in patient serum (41). In this assay, the stage of convertase formation by test sera (step 1) is separated from the standardized stage of C5b-9 formation and hemolysis (step 2) by using the $\mathrm{C} 5$ inhibitor eculizumab. We assume that all important events influencing C3 convertase activity are also reflected in the C5 convertase activity that eventually generates the readout. In this study, we aimed to modify the existing assay to distinguish between properdin-dependent and properdinindependent $\mathrm{C} 3 \mathrm{NeFs}$. For this purpose, two approaches were designed in which properdin was eliminated during the first step of convertase assembly and decay in presence of $\mathrm{C} 3 \mathrm{NeFs}$ (Figure 1). The first method assesses the ability of $\mathrm{C} 3 \mathrm{NeF}-$ positive patient Ig fractions to stabilize convertases formed out of $\triangle \mathrm{P}$-NHS. In the second assay, properdin is blocked directly in serum using the properdin-blocking tick protein Salp20 (45) to assess the ability of the $\mathrm{C} 3 \mathrm{NeFs}$ contained in serum to cause convertase stabilization. Only samples with properdinindependent $\mathrm{C} 3 \mathrm{NeFs}$ test positive in these assays.

We first investigated the effect of absence of properdin in the convertase activity assay using $\triangle \mathrm{P}$-NHS. We confirmed by ELISA that no residual properdin was detectable in this commercially obtained $\triangle \mathrm{P}$-NHS. Whereas maximal convertase 
TABLE 1 | Complement investigations in C3NeF-positive C3G patients.

\begin{tabular}{|c|c|c|c|c|c|c|c|c|c|c|c|c|c|c|}
\hline Patient & $\begin{array}{l}\text { Gender } \\
\text { (M/F) }\end{array}$ & $\begin{array}{l}\text { Age at time } \\
\text { of first } \\
\text { presentation }\end{array}$ & $\begin{array}{l}\text { Age at time } \\
\text { of study } \\
\text { (year) }\end{array}$ & Diagnosis & $\begin{array}{l}\text { Genetic } \\
\text { aberrations }\end{array}$ & $\begin{array}{l}\text { Properdin- } \\
\text { dependency } \\
\text { of C3NeF }\end{array}$ & $\begin{array}{c}\text { C3 (mg/L) } \\
{[700-1500]}\end{array}$ & $\begin{array}{c}\text { C5 }(\mu \mathrm{g} / \mathrm{ml}) \\
\text { [42-93] }\end{array}$ & $\begin{array}{l}\text { Properdin } \\
(\mu \mathrm{g} / \mathrm{ml}) \\
{[11.0-28.0]}\end{array}$ & $\begin{array}{c}\text { C3bBbP } \\
(\mathrm{CAU}) \\
{[<12]}\end{array}$ & $\begin{array}{l}\text { C3bc } \\
(\mathrm{CAU}) \\
{[<15]}\end{array}$ & $\begin{array}{l}\text { C5b-9 } \\
\text { (CAU) } \\
{[<0.5]}\end{array}$ & $\begin{array}{c}\begin{array}{c}\text { Factor H } \\
(\mu \mathrm{g} / \mathrm{ml}) \\
{[122-315]}\end{array}\end{array}$ & $\begin{array}{l}\text { Factor I } \\
(\mu \mathrm{g} / \mathrm{ml}) \\
{[22-41]}\end{array}$ \\
\hline
\end{tabular}
(year)

\section{(A) PATIENTS OF WHICH BOTH THE Ig FRACTIONS AND SERA ARE TESTED FOR PROPERDIN-DEPENDENCY OF C3NeF}

P1

P3 M 6

P4 M

P5 $\quad$ M

B) PATIENTS OF WHICH THES

C3GN

(p.R181T)

$\begin{array}{lll}\text { P7 } & \text { M } & 6 \\ \text { P8 } & \mathrm{F} & 7\end{array}$

P9 F

16

P10 F

\begin{tabular}{lcc} 
P11 & $F$ & 13 \\
& & \\
P12 & $M$ & 2 \\
P13 & $M$ & 11 \\
\hline
\end{tabular}

Complement investigations were performed at the time of study. Ref for the presence of autoantibodies against Factor H. Indicated genetic aberrations are heterozygous variations. C3GN, C3 glomerulonephritis; DDD, dense deposit disease; IC-MPGN, immune complex-mediated membranoproliferative glomerulonephritis; CFHR5, complement factor $\mathrm{H}$-related 5; C3NeF, C3 nephritic factor. 


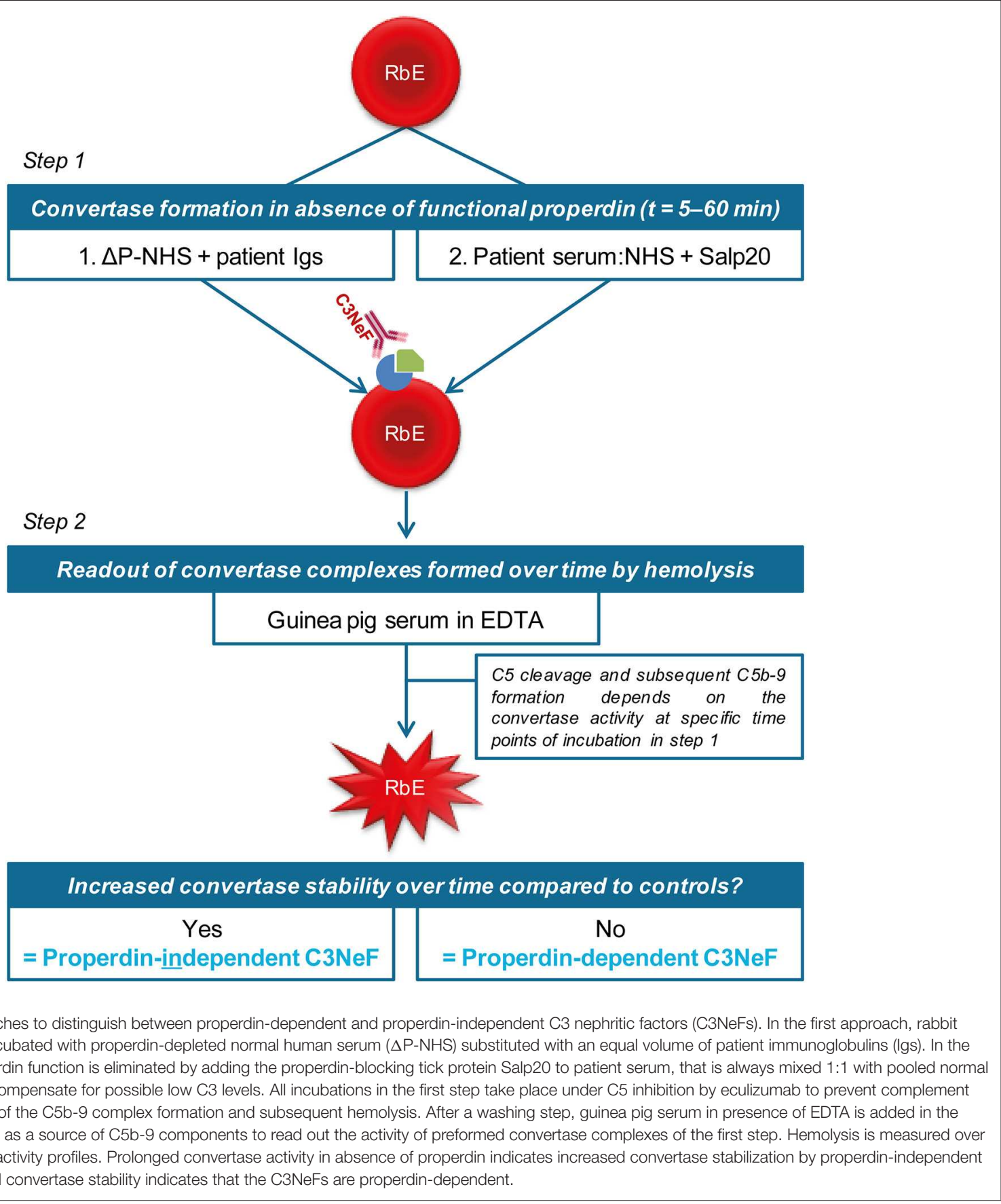

activity $\left(t_{\max }\right)$ induced by NHS is generally reached after $10-$ 15 min of incubation, the $t_{\max }$ of $\triangle \mathrm{P}$-NHS was reached after 30 min (Figure 2A). Reconstitution of $\triangle \mathrm{P}$-NHS with purified properdin restored the convertase activity dose-dependently. A normal physiological concentration of $25 \mu \mathrm{g} / \mathrm{ml}$ properdin was able to completely bring back $\mathrm{t}_{\max }$ to $15 \mathrm{~min}$ as in NHS.

Subsequently, we examined the effect of Salp20 on convertase formation and decay in the convertase activity assay. The addition of at least $3.13 \mu \mathrm{g} / \mathrm{ml}$ Salp20 (170 nM) to NHS resulted in convertase activity profiles similar to those of $\triangle \mathrm{P}-\mathrm{NHS}$ and were characterized by a delayed $t_{\max }$ of $30 \mathrm{~min}$ (Figure 2B). This supports that effective inhibition of properdin in NHS was possible using Salp20. If the properdin blocker was added in much higher concentrations, i.e., up to 100 or $200 \mu \mathrm{g} / \mathrm{ml}$ (up to $11 \mu \mathrm{M}$ ), a decrease in maximal hemolysis was observed (Figure 2C). Therefore, $6.25 \mu \mathrm{g} / \mathrm{ml}(340 \mathrm{nM})$ was chosen as the optimal concentration for properdin blockage in serum in following experiments. Altogether, both approaches showed consistent differences between the convertase activity profiles of serum in absence and presence of functional properdin. 


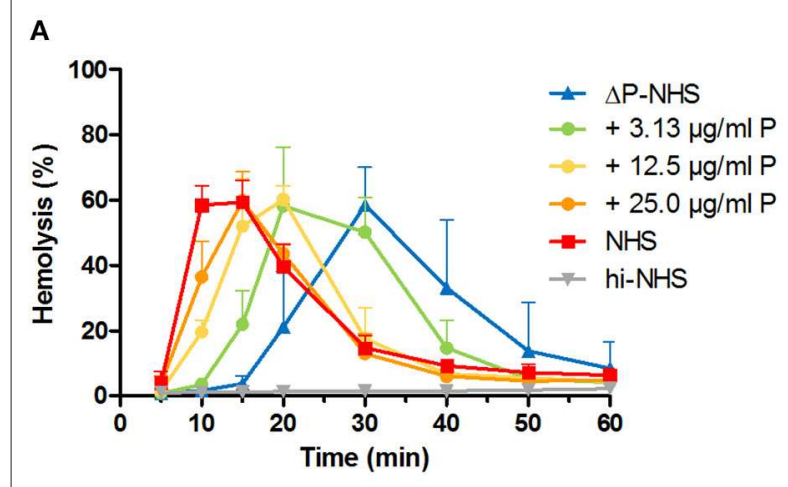

B
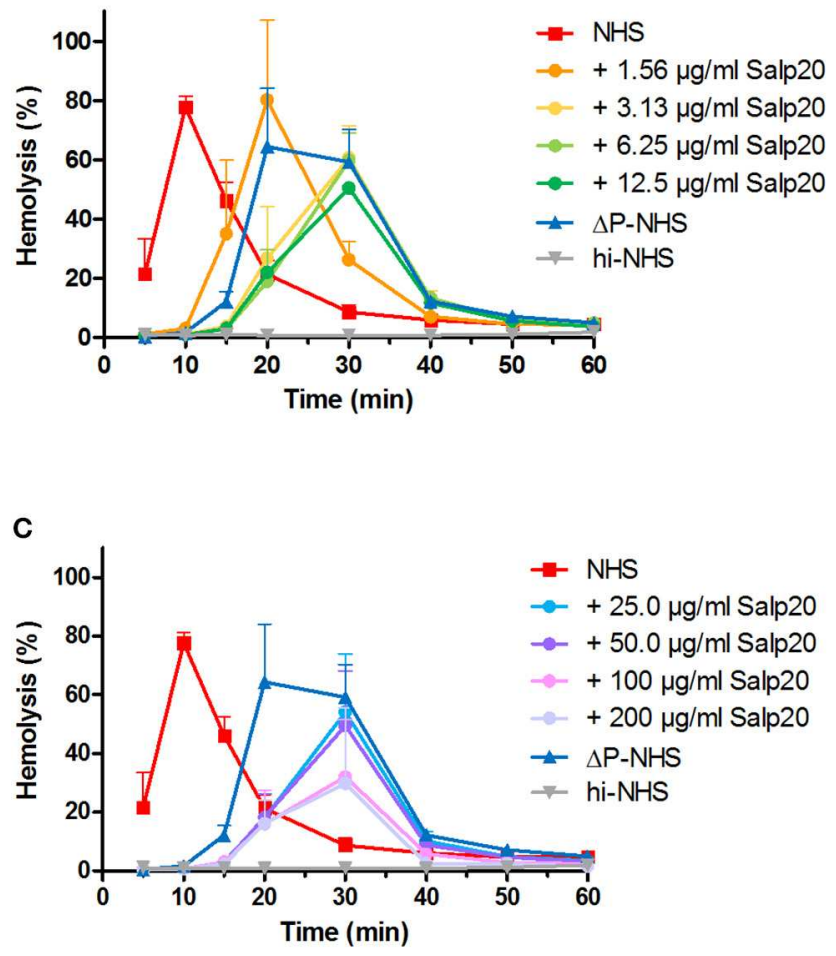

FIGURE 2 | Properdin depletion or blockage in normal human serum results in delayed maximal convertase activity. (A) Rabbit erythrocytes were incubated with properdin-depleted normal human serum ( $\triangle \mathrm{P}-\mathrm{NHS}$ ) and increasing concentrations of purified properdin $(P)$. (B,C) Alternatively, erythrocytes were incubated with pooled normal human serum (NHS) and increasing concentrations of Salp20. Protein concentrations indicated are corrected for the used serum percentages of $3.8(\mathbf{A})$ and $5.0 \%(\mathbf{B}, \mathbf{C})$. Error bars indicate standard deviations of the mean obtained from three independent experiments. hi-NHS, heat-inactivated NHS.

\section{Detection of Properdin-Dependent C3NeFs in Patient Ig Fractions}

Patients P1 to P6 all showed prolonged convertase activity in the assay under default conditions with properdin present. We confirmed that this prolonged activity was caused by convertasestabilizing autoantibodies, i.e., $\mathrm{C} 3 \mathrm{NeFs}$, by adding the purified Ig fractions of the patient samples to NHS (Figure 3). We subsequently tested the $\mathrm{C} 3 \mathrm{NeF}$ activity of patient Igs in $\Delta \mathrm{P}$ NHS. Five out of the six tested $\mathrm{C} 3 \mathrm{NeF}$-containing fractions, namely of P1, P2, P3, P5, and P6, showed significant prolongation of convertase activity when added to $\triangle \mathrm{P}-\mathrm{NHS}$ (Figure 4). In contrast, the addition of the Igs of $\mathrm{P} 4$ to $\triangle \mathrm{P}$-NHS did not induce any change in convertase stability and resulted in a profile similar to $\triangle \mathrm{P}-\mathrm{NHS}$ incubated with control Igs (NHP Igs). Thus, the $\mathrm{C} 3 \mathrm{NeF}$ activity observed in P1, P2, P3, P5, and P6 was independent of properdin, whereas the stabilizing activity of the $\mathrm{C} 3 \mathrm{NeFs}$ of $\mathrm{P} 4$ was likely dependent on presence of properdin during convertase formation.

\section{Detection of Properdin-Dependent C3NeFs in Patient Serum}

As an alternative approach, we aimed to assess the properdin dependency of $\mathrm{C} 3 \mathrm{NeF}$ directly in patient serum by blocking properdin with Salp20. Not enough serum was available for P5, so EDTA-plasma was used. This material was previously shown to be compatible with the assay (41). The C3NeFs contained in the serum or plasma of patients P2, P5, and P6 clearly retained their ability to prolong the convertase activity in the presence of Salp20 (Figure 5). The convertase activity profiles obtained from sera of patients P1, P3, and P4 were more difficult to interpret for prolonged convertase activity, since hemolysis levels were lower and maximal activity was reached at later time points compared to NHS treated with Salp20.

We hypothesized that this could be due to inadequate compensation for the low serum C3 levels in the samples under these particular properdin-lacking conditions. Using $\triangle \mathrm{C} 3$-NHS as a substitute for patient serum with very low C3 we confirmed this hypothesis. Like patient sera, $\Delta \mathrm{C} 3$ NHS was tested in a 1:1 ratio with NHS, resulting in half of the normal C3 levels. This compensation is adequate in conditions in which properdin is present (41). However, in serum conditions with properdin absent or inhibited by Salp20, reduced C3 levels by half significantly altered the activity profile characterized by a $t_{\max }$ reached at $50 \mathrm{~min}$ (Figure 6A). Such activity profile does not allow analysis for prolongation of convertase activity after $t_{\max }$ is reached. The addition of $\mathrm{C} 3$ to reach physiological levels could restore the activity profile and $t_{\max }$ dose-dependently (Figure 6B).

Thus, samples P1, P3, and P4 were supplemented with 250 and $500 \mu \mathrm{g} / \mathrm{ml}$ purified C3 to shift hemolysis peaks to earlier time points comparable to those of samples with normal C3. This recovered the experimental time window to assess the activity profiles and clearly revealed that the C3NeFs of $\mathrm{P} 1$ and P3 still caused convertase stabilization in absence of functional properdin, whereas those of $\mathrm{P} 4$ did not (Figure 5). As a control, the addition of $\mathrm{C} 3$ to $\mathrm{P} 2$ and $\mathrm{P} 5$ only resulted in a slightly faster generation of $\mathrm{t}_{\max }$, but it did not alter the prolonged convertase activity present in these patients (Supplementary Figure 1). These results obtained with the Salp20 method correspond to those generated with $\triangle \mathrm{P}$-NHS and Igs and further support the properdin-dependency of the $\mathrm{C} 3 \mathrm{NeFs}$ of $\mathrm{P} 4$. 
P1

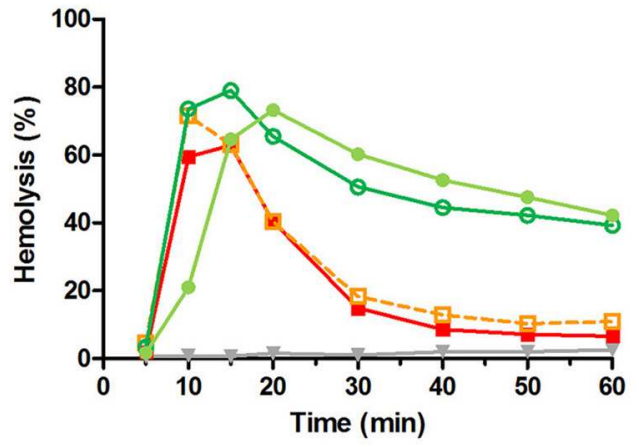

P3

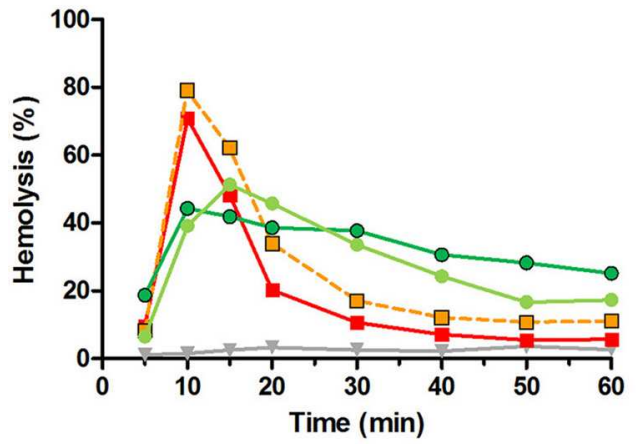

P5

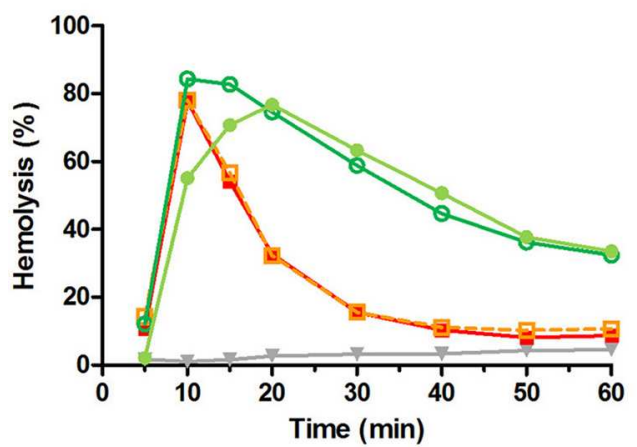

P2

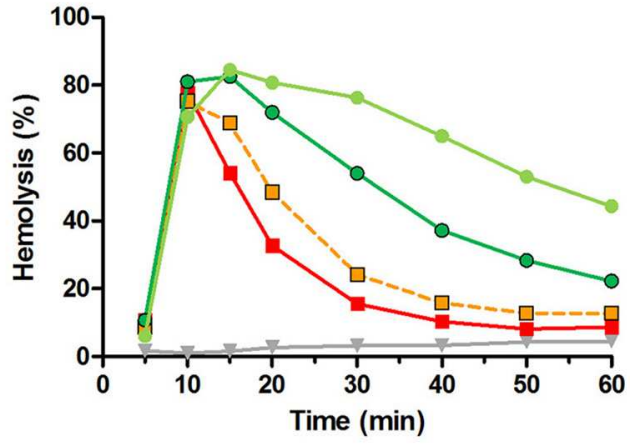

P4

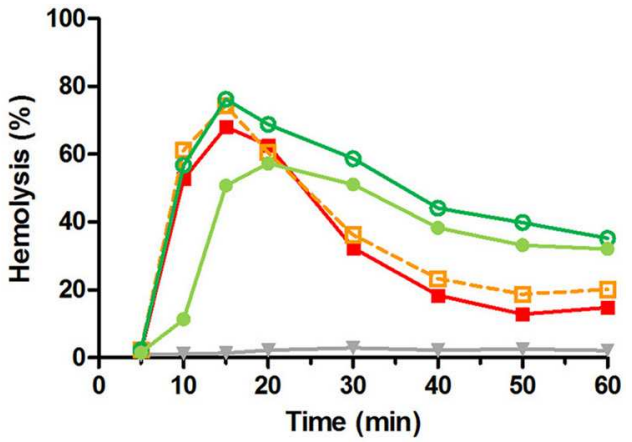

P6

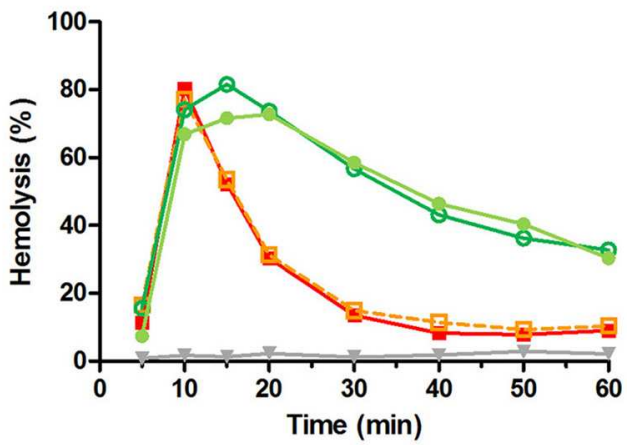

\begin{tabular}{|c|c|c|}
\hline- Patient serum & $\rightarrow \mathrm{NHS}$ & $\mp$ hi-NHS \\
\hline$\curvearrowleft$ NHS + Patient Igs (1:1) & $-\exists \cdot \quad \mathrm{NHS}+\mathrm{NHP}$ Igs $(1: 1)$ & \\
\hline-0 NHS + Patient Igs (1:3) & $-\square \cdot \quad \mathrm{NHS}+\mathrm{NHP}$ Igs (1:3) & \\
\hline
\end{tabular}

FIGURE 3 | C3NeF activity in patient sera and patient immunoglobulins (lgs). Rabbit erythrocytes were incubated with pooled normal human serum (NHS) mixed with an equal volume of serum of patients P1, P2, P3, P4, and P6 or EDTA-plasma of P5 to a final concentration of $5 \%$. Alternatively, erythrocytes were incubated with NHS mixed with an equal volume (1:1; P1, P4, P5, and P6) or 3-fold volume (1:3; P2 and P3) of purified Igs derived from patient samples or with control lgs derived from pooled normal human EDTA-plasma (NHP). Representative data of at least two independent experiments are shown. hi-NHS, heat-inactivated NHS. 
P1

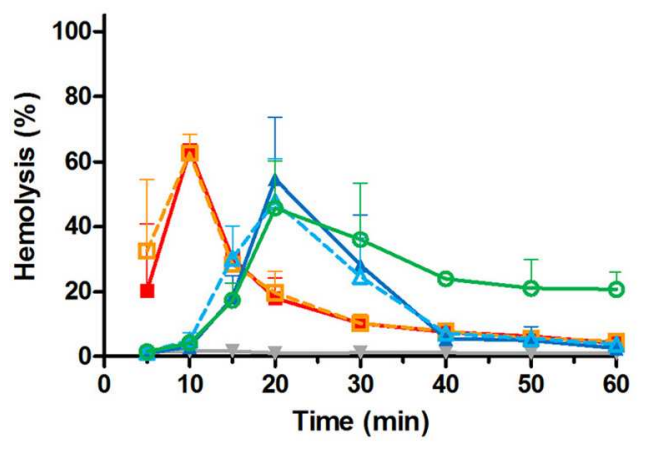

P3

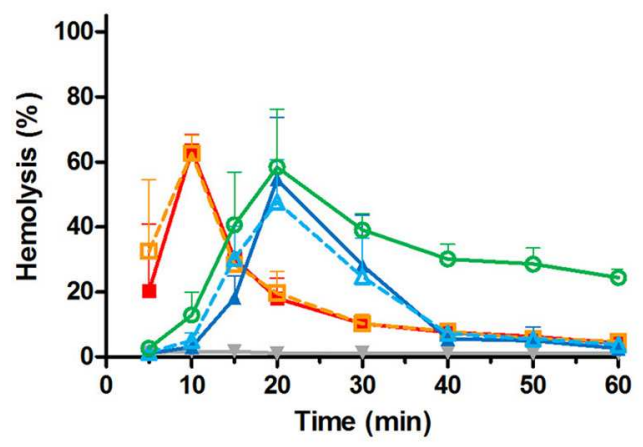

P5

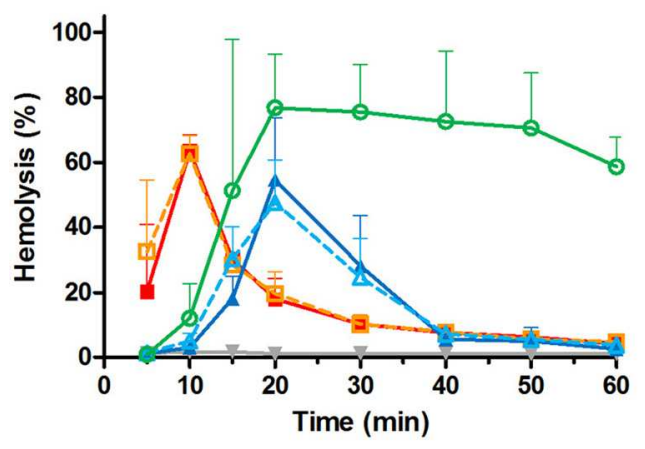

P2

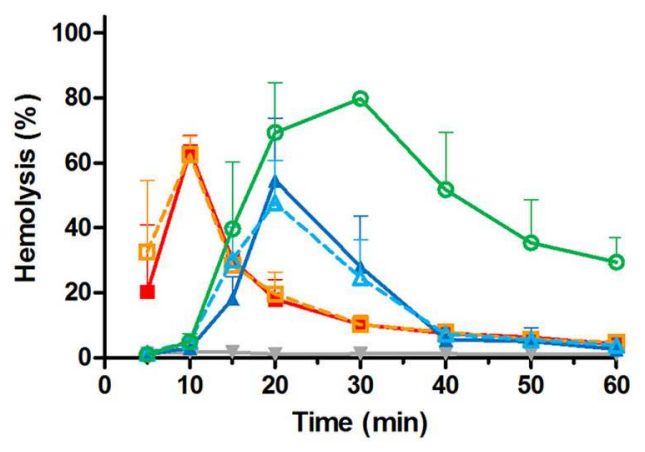

P4

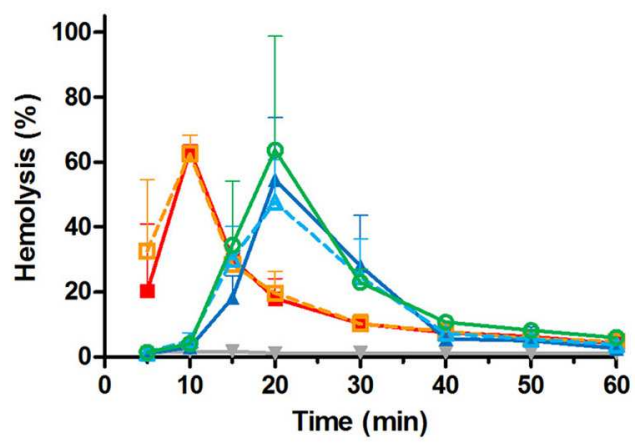

P6

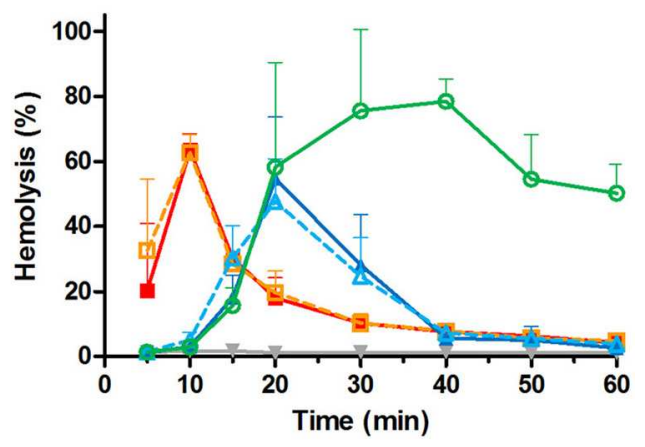

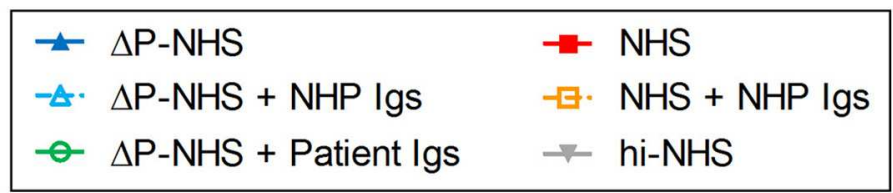

FIGURE 4 | Detection of properdin-dependent and properdin-independent C3NeFs in C3G patients using properdin-depleted normal human serum ( $\triangle \mathrm{P}-\mathrm{NHS}$ ) and patient immunoglobulins (Igs). Rabbit erythrocytes were incubated with $5 \% \Delta \mathrm{P}-\mathrm{NHS}$ mixed with an equal volume of purified lgs from patients P1, P2, P3, P4, P5, and P6 or with control Igs derived from pooled normal human EDTA-plasma (NHP). Error bars indicate standard deviations of the mean obtained from three independent experiments. NHS, pooled normal human serum; hi-NHS, heat-inactivated NHS. 
P1

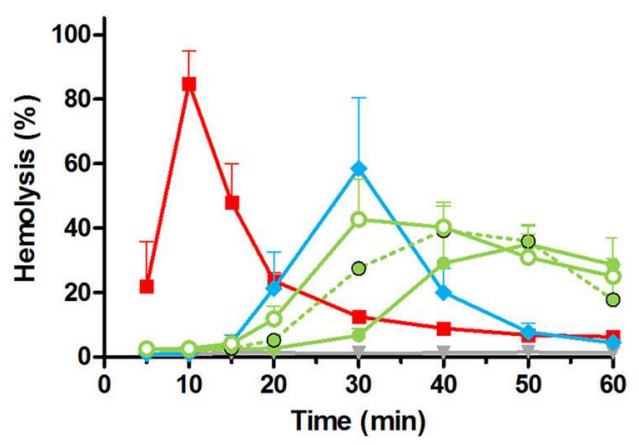

P3

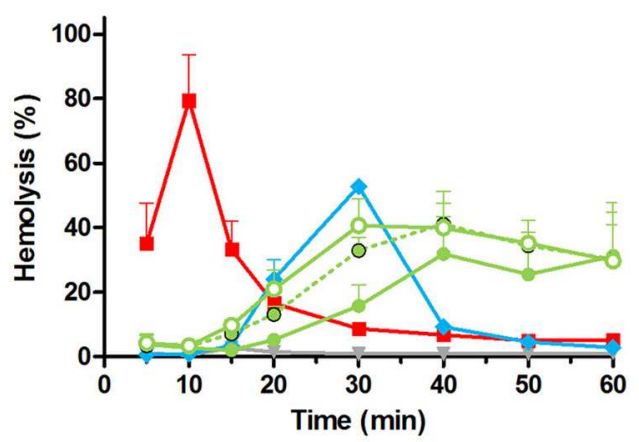

P5

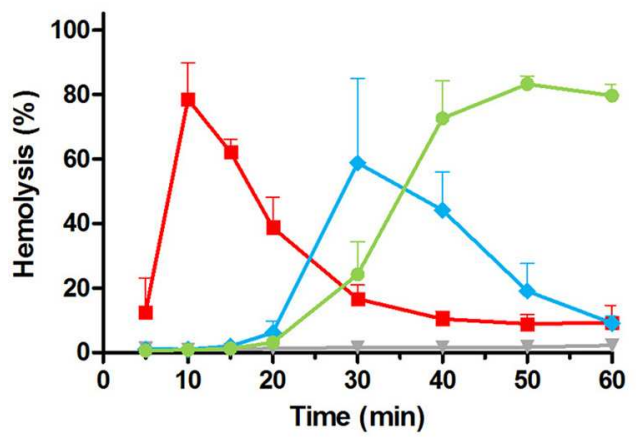

P2

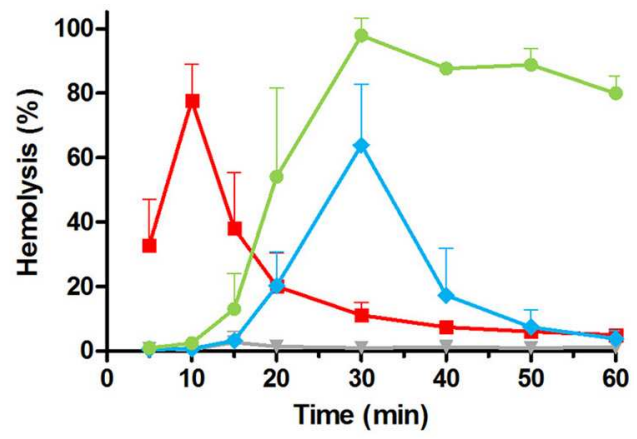

P4

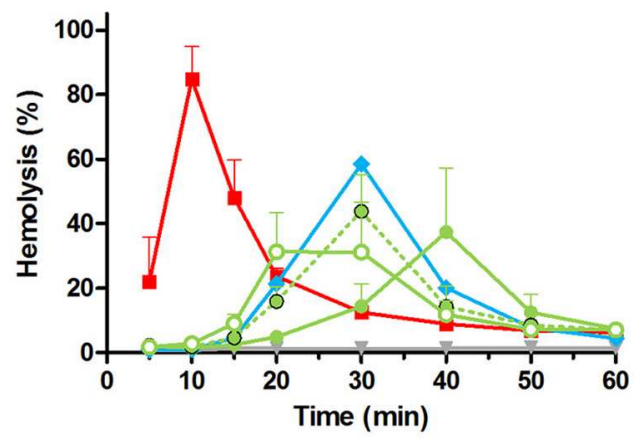

P6

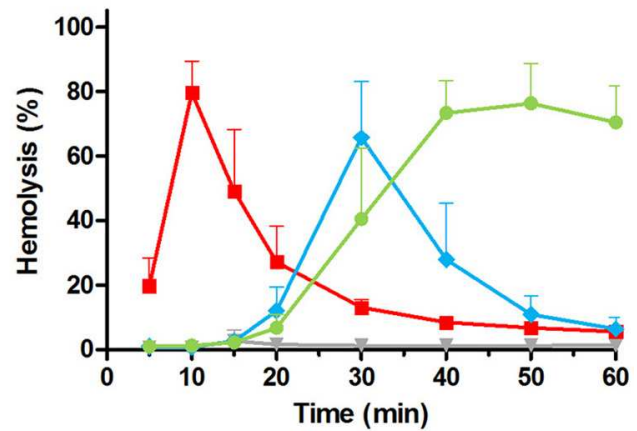

\begin{tabular}{|c|c|}
\hline$\rightarrow-$ Patient serum + Salp20 & $\rightarrow \mathrm{NHS}+$ Salp20 \\
\hline - - Patient serum + Salp20 + $250 \mu \mathrm{g} / \mathrm{ml} \mathrm{C3}$ & $\rightarrow$ NHS \\
\hline -o- Patient serum + Salp20 + 500 $\mu \mathrm{g} / \mathrm{ml} \mathrm{C3}$ & $\rightarrow$ hi-NHS \\
\hline
\end{tabular}

FIGURE 5 | Detection of properdin-dependent and properdin-independent C3NeFs in C3G patients using patient serum and the properdin inhibitor Salp20. Rabbit erythrocytes were incubated with pooled normal human serum (NHS) mixed with an equal volume of serum of patients P1, P2, P3, P4, and P6 or EDTA-plasma of P5 to a final concentration of $5 \%$ and in presence of $6.25 \mu \mathrm{g} / \mathrm{ml}$ Salp20. Additionally, purified C3 was added for the samples of P1, P3, and P4, according to the concentrations indicated, which are corrected for the used serum percentage. Error bars indicate standard deviations of the mean obtained from three independent experiments. $\triangle$ P-NHS, properdin-depleted normal human serum; hi-NHS, heat-inactivated NHS. 


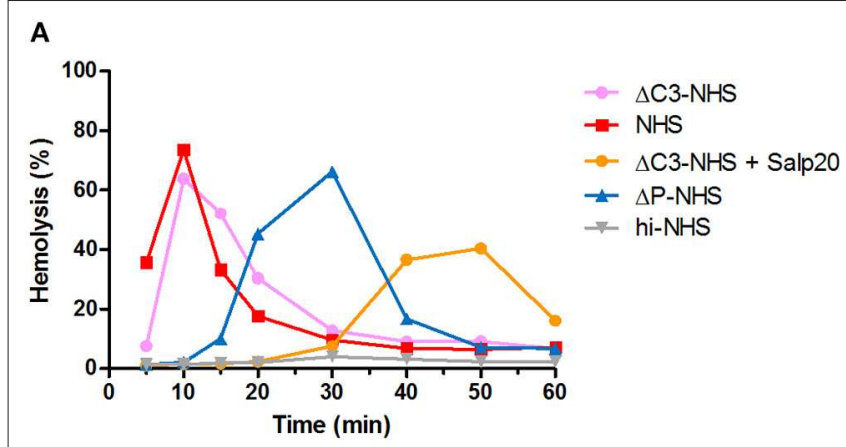

B

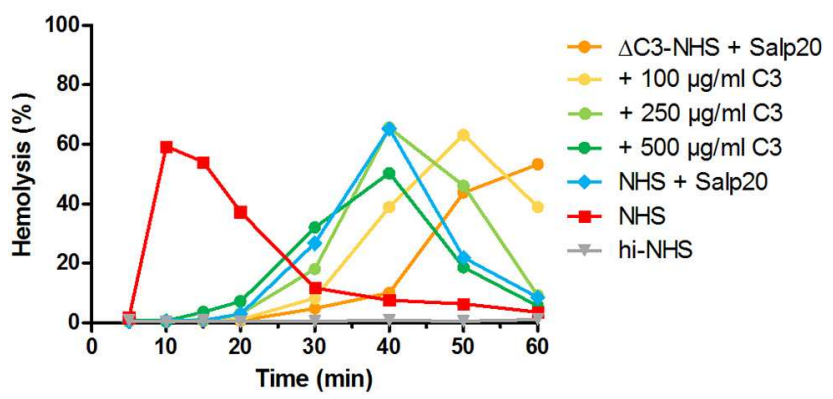

FIGURE 6 | Effect of low serum C3 concentration on the convertase activity profile of serum treated with Salp20. (A) Rabbit erythrocytes were incubated with C3-depleted normal human serum ( $\triangle \mathrm{C} 3-\mathrm{NHS}$ ) mixed with an equal volume of pooled normal human serum (NHS) in absence or presence of 6.25 $\mu \mathrm{g} / \mathrm{ml}$ Salp20. (B) Alternatively, $\Delta$ C3-NHS samples treated with Salp20 were supplemented with increasing concentrations of purified C3. Concentrations indicated are corrected for the used serum percentages of 5.0 (A) and 3.8\% (B). Representative data of at least two independent experiments are shown. $\triangle \mathrm{P}-\mathrm{NHS}$, properdin-depleted normal human serum; hi-NHS, heat-inactivated NHS.

\section{Properdin Restores the Convertase-Stabilizing Activity of Properdin-Dependent C3NeFs in a C3G Patient}

To confirm the properdin-dependency of the C3NeFs of P4, functional properdin was restored in both assays by either reconstituting the $\triangle \mathrm{P}$-NHS with purified properdin or by titrating Salp20 to lower, ineffective concentrations in the patient serum. Convertase stabilization by P4 Igs completely returned upon addition of purified properdin in concentrations of $6.25 \mu \mathrm{g} / \mathrm{ml}$ or higher (Figure 7A). In a similar way, titration of Salp20 to concentrations below $6.25 \mu \mathrm{g} / \mathrm{ml}$ restored the convertase stabilization by $\mathrm{C} 3 \mathrm{NeFs}$ in the serum of $\mathrm{P} 4$ (Figure 7B). Availability of functional properdin also resulted in a shift of $t_{\max }$ to earlier time points, as we previously observed in Figure 2. Except for this peak shift, properdin reconstitution in the samples of $\mathrm{P} 1$ and $\mathrm{P} 2$, containing properdinindependent $\mathrm{C} 3 \mathrm{NeF}$, did not affect the convertase stabilization (Figures 7C,D). In conclusion, these experiments support our previous findings that the convertase-stabilizing activity by $\mathrm{P} 4$ $\mathrm{C} 3 \mathrm{NeFs}$ was dependent on properdin.

\section{Screening for Properdin-Dependent C3NeFs in Patient Sera Using the Salp20 Method}

After the validation of our methods to detect properdindependent $\mathrm{C} 3 \mathrm{NeFs}$ in six patients, we then applied the method using Salp20 for $\mathrm{C} 3 \mathrm{NeF}$ characterization in seven other patient sera that we tested positive for $\mathrm{C} 3 \mathrm{NeF}$ (Figures 8A,B). We chose this Salp20 method for the screening as it is less time consuming (no Ig purification) and it requires less patient material. Regardless of the $\mathrm{C} 3$ levels of these samples, we first decided to test all samples with Salp20 to block properdin but without the addition of extra C3 (Figures 8C,D). In 4 out of 7 samples, we observed that $t_{\max }$ was generated at later time points compared to NHS treated with Salp20, thereby reducing the time window in which convertase activity could be assessed. Hence, these samples, belonging to P8, P10, P11, and P13, were selected for $\mathrm{C} 3$ compensation with 250 and $500 \mu \mathrm{g} / \mathrm{ml}$ C3 (Figures 8E-H). This approach enabled a clear and reliable assessment of the convertase activity profiles under properdin blockade. The sera of patients P10 and P13 were completely unable to cause prolonged convertase activity when properdin was blocked (Figures $\mathbf{8 G}, \mathbf{H}$ ). Thus, the $\mathrm{C} 3 \mathrm{NeF}$ activity in P10 and P13 was properdin-dependent, whereas the convertasestabilizing activity in the other five patients was detected independent of properdin.

In total, we analyzed 13 pediatric patients in this study, three of which carry properdin-dependent $\mathrm{C} 3 \mathrm{NeFs}$.

\section{DISCUSSION}

Patients with C3G have a variable disease course and can present with heterogeneous genetic backgrounds and complement activation profiles. This complicates therapeutic choices. The careful characterization of different types of $\mathrm{C} 3 \mathrm{NeF}$, such as properdin-dependent and properdin-independent $\mathrm{C} 3 \mathrm{NeFs}$, may enable a better understanding of the underlying complement problems and provide better patient stratification. More importantly, it might lead to new therapeutic options for C3G patients. This also holds true for patients diagnosed with IC-MPGN, in which C3NeFs are also common (5). We hypothesized that inhibiting properdin can compensate for the convertase-stabilizing effect of properdin-dependent C3NeFs. In this study, we optimized two simple and reliable methods to distinguish between properdin-dependent and properdinindependent C3NeFs. Of the $12 \mathrm{C} 3 \mathrm{G}$ patients and 1 IC-MPGN patient we tested, 3 patients were found positive for having properdin-dependent $\mathrm{C} 3 \mathrm{NeFs}$. For these patients, we showed in vitro proof-of-concept that properdin inhibition in serum could normalize the convertase activity.

The described assays assess the ability of C3NeFs to stabilize convertases formed out of serum in which properdin is eliminated using $\triangle \mathrm{P}$-NHS or the properdin-inhibiting protein Salp20 (Figure 1). Hereby, they allow the strict distinction between $\mathrm{C} 3 \mathrm{NeFs}$ that do or do not function in absence of properdin in a serum environment. Our approaches resemble those initially developed in the late 80s/90s: they are based on 
A

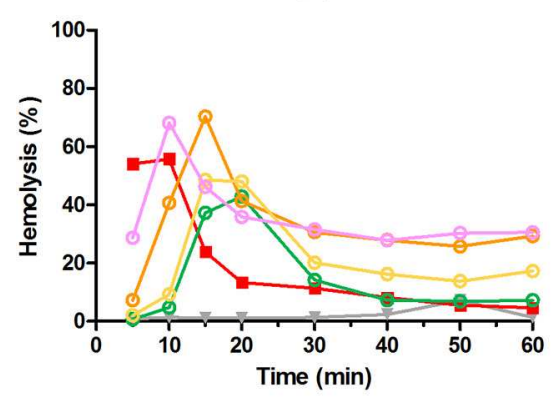

C

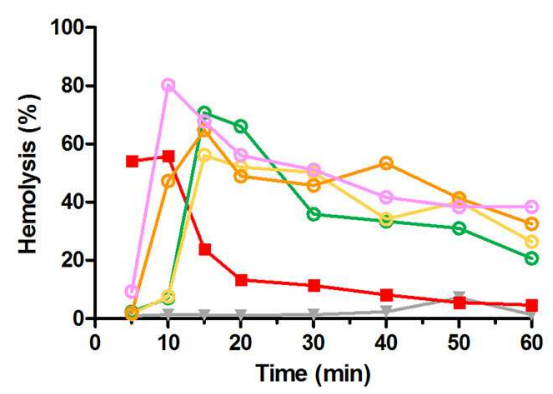

B
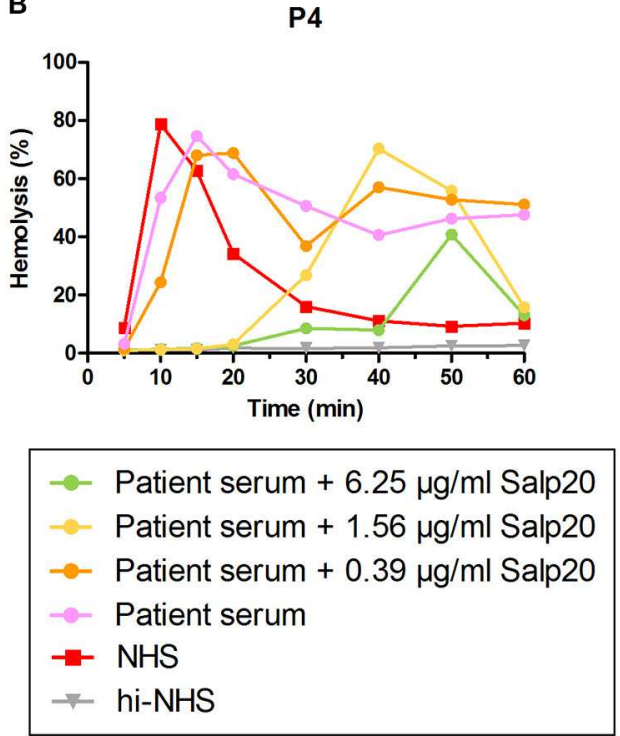

D

P2

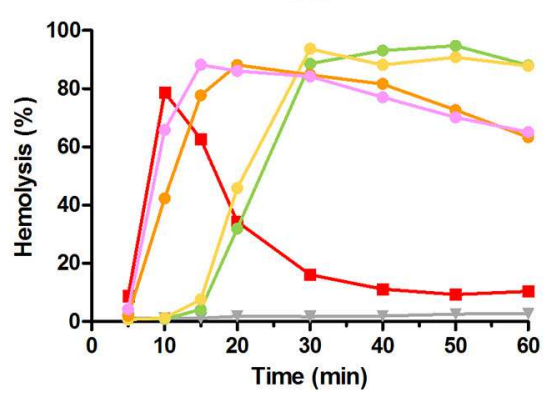

FIGURE 7 | Convertase-stabilizing activity of properdin-dependent but not properdin-independent C3NeFs is restored in presence of functional properdin. Patient immunoglobulins (Igs) of P4 (A) and P1 (C) were incubated with properdin-depleted normal human serum ( $\triangle \mathrm{P}-\mathrm{NHS})$, and were reconstituted with increasing concentrations of purified properdin (P). Alternatively, Salp20 was titrated into the patient sera of patient P4 (B) and P2 (D), that were tested mixed with an equal volume of pooled normal human serum (NHS). Protein concentrations indicated are corrected for the used serum percentage of $5 \%$. Representative data of at least two independent experiments are shown. hi-NHS, heat-inactivated NHS.

removing properdin from the default assay conditions $(33,34)$. In contrast, most of the recently published studies determined the properdin-dependency of $\mathrm{C} 3 \mathrm{NeF}$ s by adding properdin to the default conditions $(4,27,31)$. These studies showed that some $\mathrm{C} 3 \mathrm{NeF}$ s could not be detected when the stabilization of the $\mathrm{C} 3 \mathrm{bBb}$ complex was assessed but could be detected when $\mathrm{C} 3 \mathrm{bBbP}$ stabilization was investigated $(4,27,31)$. The convertase complexes in these studies were formed using purified components on the platform of sheep erythrocytes or an ELISAplate. The advantage of the assays described in our study is that convertase formation takes place in a whole serum environment, which more closely resembles physiological conditions regarding convertase formation and regulation. Therefore, they are more likely to reveal physiologically relevant stabilizing factors. Nonetheless, in the current setting, a standardized serum source is used as well as a rabbit erythrocyte platform, which is not comparable to the glomerular structures in terms of surface binding places for complement regulators and complement inhibitors expressed. Future research may focus on further assay optimization using human (glomerular) cells.

The two validated assays presented here have their own benefits and drawbacks. The assay that tests the capability of patient Igs to stabilize convertases formed out of $\triangle \mathrm{P}$-NHS has the advantage that it directly confirms the autoantibody nature of the convertase-stabilizing factor present in the patient. In addition, it uses a standardized commercial source for convertase formation and thereby reduces assay variability. On the other hand, this approach requires Ig purification which is a relatively time-consuming step requiring a high volume of patient material. The second assay, in which the properdin dependency is assessed directly in patient serum mixed with NHS in presence of Salp20, has the advantage that it resembles the physiological situation in the patient more closely. Also, there is no need for Ig purification (making the assay less time consuming) and 


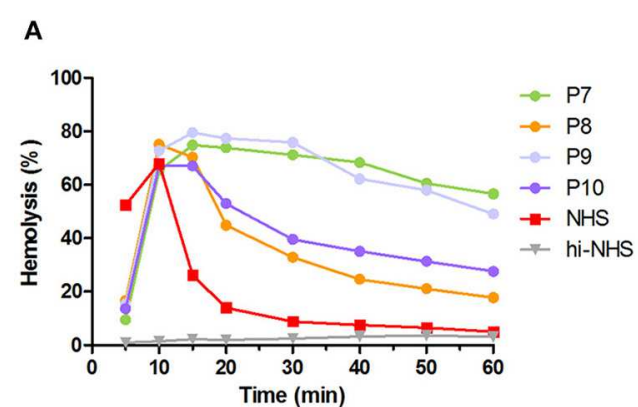

C

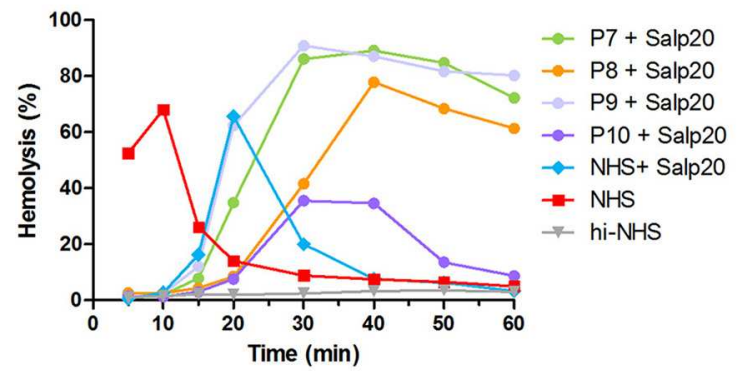

E

P8

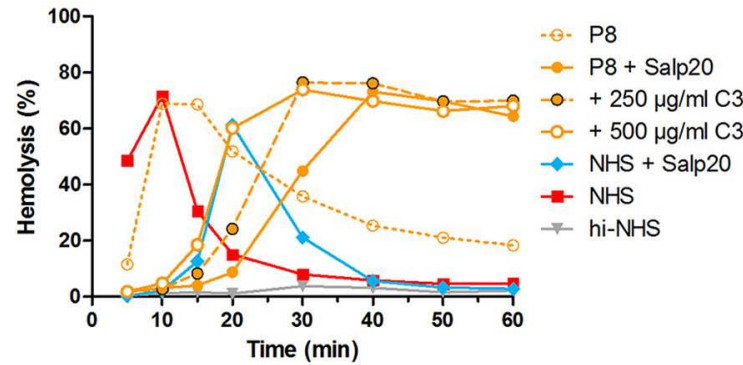

G

P10

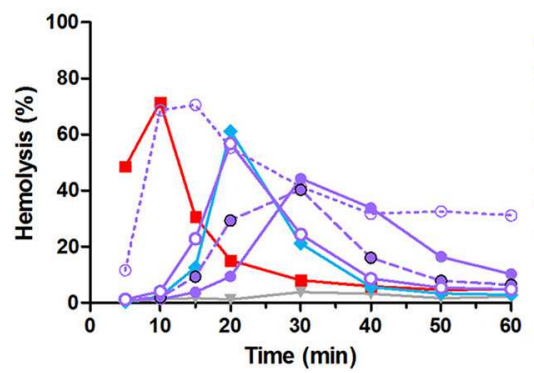

B

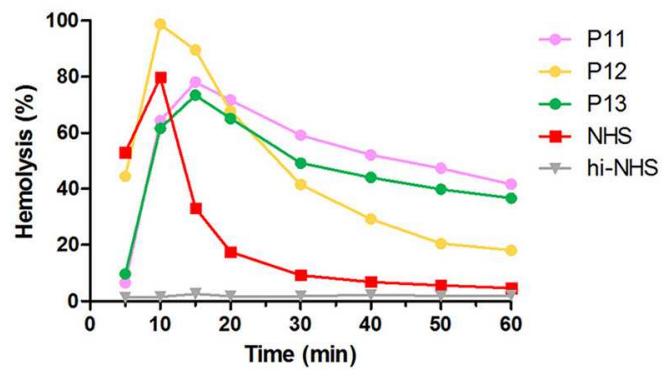

D

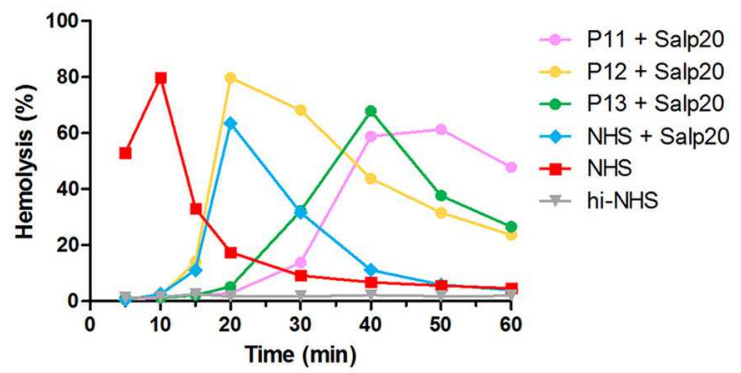

F

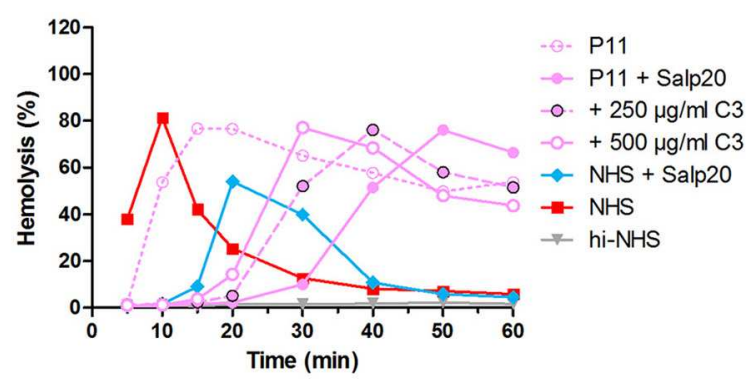

H

P13

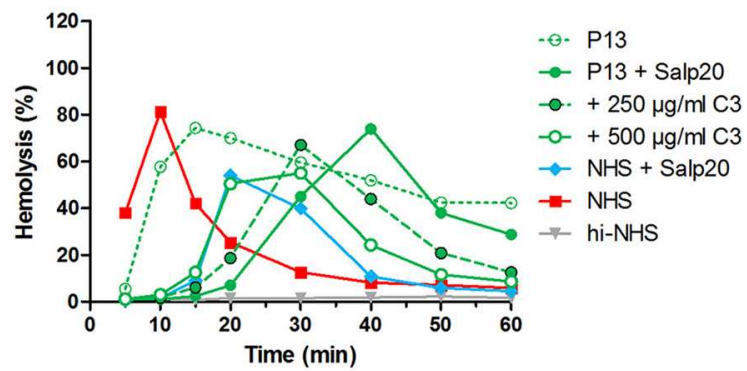

FIGURE 8 | Screening for properdin-dependent C3NeFs in patient sera using the Salp20 method. Convertase activity was assessed in the serum of patients P7-P13 mixed with an equal volume of pooled normal human serum (NHS) to a final percentage of $3.8 \%$ (A,B). Convertase activity in absence of properdin was assessed by adding $6.25 \mu \mathrm{g} / \mathrm{ml}$ Salp20 to these samples (C,D). For P8, P10, P11, and P13, convertase activity was also assessed after compensation for C3 by adding 250 and $500 \mu \mathrm{g} / \mathrm{ml}$ purified C3 to the samples (E-H). All concentrations indicated have been corrected for the used serum percentage of $3.8 \%$. Representative data of at least two independent experiments are shown. hi-NHS, heat-inactivated NHS. 
the amount of serum needed is minimal. For this reason, we chose this method to screen for other properdin-dependent $\mathrm{C} 3 \mathrm{NeFs}$ in additional patient sera. However, we found that for some serum samples with very low C3 levels and late onset of $t_{\max }$, compensation with purified $\mathrm{C} 3$ was needed to create an experimental time window allowing the reliable assessment of the convertase activity profiles (Figures 5, 8). This indicates that experimental conditions should be well-optimized and wellregulated. Both assays can be easily incorporated in routine laboratories with expertise in complement methods to be used for patient screening.

Some studies have reported that properdin-dependency of C3NeFs correlates with complement biomarker profiles in various patient groups. Properdin-dependent $\mathrm{C} 3 \mathrm{NeFs}$ were associated with C5 convertase dysregulation and activation of the terminal pathway, whereas properdin-independent $\mathrm{C} 3 \mathrm{NeFs}$ were predominantly associated with C3 convertase dysregulation $(4,33,34)$. In our study with a small number of patients, we did not observe such correlations. Decreased C3 and C5 levels and increased C5b-9 levels were observed with both types of C3NeF (Table 1). Future research with larger patient numbers may shed light on the mechanism of action of different circulating $\mathrm{C} 3 \mathrm{NeF}$ types and the association with complement (activation) markers.

During assay development, we gained important insights in the dynamic process of convertase assembly and decay in presence or absence of properdin. Using the convertase activity assays, we showed that in absence of properdin, convertase readout was obtained after a much longer incubation time (Figure 2). These results indicate that in absence of this convertase-stabilizing protein, convertase formation was less efficient. The process could be easily restored upon addition of purified properdin in a dose-dependent manner. Thus, our assay can be used as a platform for future experiments to study properdin functionality.

In addition, using the Salp20 method we observed that convertase assembly, especially in absence of properdin, depended on C3 levels (Figure 6). Addition of purified C3 to serum samples with low C3 levels could shift the delayed $t_{\max }$ to earlier time points and restore the ability to analyse the samples for convertase stabilization (Figures 5, 6, 8). Interestingly, the samples of P5, P7, P9, and to a lesser extent P2, also had C3 levels below the normal range but did not require $\mathrm{C} 3$ supplementation. The potency of serum to support efficient convertase formation depends not only on C3 concentration but also on other complement (regulatory) proteins (and possibly C3NeFs), which may altogether give favorable profiles even in combination with low C3 in some patients. Nevertheless, in general, the patients who did require $\mathrm{C} 3$ supplementation (P1, P3, P4, P8, P10, P11, and $\mathrm{P} 13$ ) all have low $\mathrm{C} 3$ levels, whereas the only ones with $\mathrm{C} 3$ levels within the normal range (P6 and P12) did not require $\mathrm{C} 3$ supplementation for analysis.

Previous studies have shown that Salp20 displaces properdin from the convertase due to the higher affinity of properdin for Salp20 than for C3b $(45,46)$. In our hands, Salp20 was indeed an effective inhibitor of properdin (Figure 2). It has been shown that Salp20 is highly specific for properdin inhibition $(45,46)$. No other functions of Salp20 have been reported, and we did not encounter any critical side effects of Salp20 in current assay settings. Though, we cannot explain why high Salp20 concentrations partially inhibited maximal hemolysis levels (Figure 2C).

Using Salp20 as a model, we here evaluated the potential of properdin-inhibiting therapy in patients with properdindependent C3NeFs. Salp20 could effectively block properdin and normalize the prolonged convertase activity caused by properdin-dependent $\mathrm{C} 3 \mathrm{NeF}$ s in $\mathrm{P} 4, \mathrm{P} 10$, and $\mathrm{P} 13$ (Figures 5, 6, 8). In patients with properdin-independent $\mathrm{C} 3 \mathrm{NeFs}$, properdin inhibition did not affect the increased convertase stability. These results support that properdin inhibition has a therapeutic potential for patients with properdin-dependent $\mathrm{C} 3 \mathrm{NeFs}$, but not for patients with properdin-independent $\mathrm{C} 3 \mathrm{NeFs}$. For the latter, alternative therapeutic strategies are needed, e.g., inhibition at the level of C3 in other ways.

Blocking properdin seems a relatively safe approach for humans, since properdin-deficient individuals do not show a severely compromised immune function, apart from the increased susceptibility to meningitis for which vaccination is possible $(47,48)$. Few studies have described blocking antihuman properdin antibodies or human properdin-competing compounds so far, and some were used in in vitro and ex vivo complement-mediated disease models (49-54). Nevertheless, therapy directed at blocking properdin must be considered with care, since studies in mice have shown that inhibition of properdin might result in unexpected outcomes (20). In two separate $\mathrm{C} 3 \mathrm{G}$ mouse models, it was shown that blocking properdin exacerbated instead of improved disease outcome $(55,56)$. However, these models were not initiated by $\mathrm{C} 3 \mathrm{NeF}$ activity but by absence of functional $\mathrm{FH}$, a cause which only occurs in rare cases of human C3G. Thus, upon properdininhibition, the initial cause of the overactive complement activity, namely dysfunctional $\mathrm{FH}$, still remained present. In individuals in which properdin-dependent $\mathrm{C} 3 \mathrm{NeFs}$ are responsible for the complement overactivity, blockage of properdin tackles the causing factor (albeit indirectly). Further in vivo experiments using human-compatible properdin blockers are needed to investigate the therapeutic potential of properdin inhibition in C3G patients. Potentially, temporary therapy with a properdin inhibitor might already be enough to bring patients back to a state of normal complement homeostasis.

In conclusion, we here demonstrated two simple, timeeffective, and reliable methods to distinguish between properdindependent and properdin-independent $\mathrm{C} 3 \mathrm{NeF}$. We also showed that properdin inhibition in patients with properdin-dependent $\mathrm{C} 3 \mathrm{NeFs}$ may be a viable therapeutic strategy to normalize convertase activity.

\section{ETHICS STATEMENT}

This study was carried out in accordance with the recommendations of the appropriate version of the Declaration of Helsinki. All subjects gave written informed consent, and the protocol was approved by the ethical committee of the Radboud University Medical Center (FH 06979). 


\section{AUTHOR CONTRIBUTIONS}

Concept of the study: MM, EV, LvdH, and NvdK. Design of the experiments: MM, EV, and LvdH. Experimental work: MM, TvdV, SvK, SS, RvdB. Data analysis: MM, NvdK, RvdB, $\mathrm{EV}$, and $\mathrm{LvdH}$. Collection and characterization of clinical samples (including genetic data): MM, NvdK, VG, MO, EV, and $\mathrm{LvdH}$. Manuscript writing: MM. All the authors approved the manuscript.

\section{FUNDING}

This work was supported by a grant from the Dutch Kidney Foundation (13OCA27 COMBAT Consortium).

\section{ACKNOWLEDGMENTS}

This study was performed on behalf of the COMBAT Consortium. This is an interuniversity collaboration in the Netherlands that is formed to study basic mechanisms, assay development, and therapeutic translation of complementmediated renal diseases. Principal investigators are (in

\section{REFERENCES}

1. Fakhouri F, Fremeaux-Bacchi V, Noel LH, Cook HT, Pickering MC. C3 glomerulopathy: a new classification. Nat Rev Nephrol. (2010) 6:494-9. doi: $10.1038 /$ nrneph.2010.85

2. Pickering MC, D'Agati VD, Nester CM, Smith RJ, Haas M, Appel GB, et al. C3 glomerulopathy: consensus report. Kidney Int. (2013) 84:1079-89. doi: $10.1038 / \mathrm{ki} .2013 .377$

3. Medjeral-Thomas NR, O'Shaughnessy MM, O'Regan JA, Traynor C, Flanagan M, Wong L, et al. C3 glomerulopathy: clinicopathologic features and predictors of outcome. Clin J Am Soc Nephrol. (2014) 9:46-53. doi: 10.2215/CJN.04700513

4. Marinozzi MC, Chauvet S, Le Quintrec M, Mignotet M, Petitprez $\mathrm{F}$, Legendre C, et al. C5 nephritic factors drive the biological phenotype of C3 glomerulopathies. Kidney Int. (2017) 92:1232-41. doi: 10.1016/j.kint.2017.04.017

5. Iatropoulos P, Daina E, Curreri M, Piras R, Valoti E, Mele C, et al. Cluster analysis identifies distinct pathogenetic patterns in C3 glomerulopathies/immune complex-mediated membranoproliferative GN. J Am Soc Nephrol. (2018) 29:283-94. doi: 10.1681/ASN.20170 30258

6. Rabasco C, Cavero T, Roman E, Rojas-Rivera J, Olea T, Espinosa M, et al. Effectiveness of mycophenolate mofetil in C3 glomerulonephritis. Kidney Int. (2015) 88:1153-60. doi: 10.1038/ki.2015.227

7. Lu DF, Moon M, Lanning LD, McCarthy AM, Smith RJ. Clinical features and outcomes of 98 children and adults with dense deposit disease. Pediatr Nephrol. (2012) 27:773-81. doi: 10.1007/s00467-011-2059-7

8. Servais A, Noel LH, Roumenina LT, Le Quintrec M, Ngo S, Dragon-Durey MA, et al. Acquired and genetic complement abnormalities play a critical role in dense deposit disease and other C3 glomerulopathies. Kidney Int. (2012) 82:454-64. doi: 10.1038/ki.2012.63

9. Bomback AS, Santoriello D, Avasare RS, Regunathan-Shenk R, Canetta PA, Ahn W, et al. C3 glomerulonephritis and dense deposit disease share a similar disease course in a large United States cohort of patients with C3 glomerulopathy. Kidney Int. (2018) 93:977-85. doi: 10.1016/j.kint.2017. 10.022

10. Riedl M, Thorner P, Licht C. C3 glomerulopathy. Pediatr Nephrol. (2017) 32:43-57. doi: 10.1007/s00467-015-3310-4 alphabetical order): S. Berger (Department of Internal Medicine-Nephrology, University Medical Center Groningen, Groningen, Netherlands), J. van den Born (Department of Internal Medicine-Nephrology, University Medical Center Groningen, Groningen, Netherlands), P. Gros (Department of Chemistry, Utrecht University, Utrecht, Netherlands), LvdH (Department of Pediatric Nephrology, Radboud University Medical Center, Nijmegen, Netherlands), NvdK (Department of Pediatric Nephrology, Radboud University Medical Center, Nijmegen, Netherlands), C. van Kooten (Department of Internal Medicine-Nephrology, Leiden University Medical Center, Leiden, Netherlands), M. Seelen (Department of Internal Medicine-Nephrology, University Medical Center Groningen, Groningen, Netherlands), A. de Vries (Department of Internal Medicine-Nephrology, Leiden University Medical Center, Leiden, Netherlands). A special thanks to J. Tijhuis.

\section{SUPPLEMENTARY MATERIAL}

The Supplementary Material for this article can be found online at: https://www.frontiersin.org/articles/10.3389/fimmu. 2019.01350/full\#supplementary-material

11. Hou J, Markowitz GS, Bomback AS, Appel GB, Herlitz LC, Barry Stokes M, et al. Toward a working definition of C3 glomerulopathy by immunofluorescence. Kidney Int. (2014) 85:450-6. doi: 10.1038/ki.2013.340

12. Goodship TH, Cook HT, Fakhouri F, Fervenza FC, Fremeaux-Bacchi V, Kavanagh D, et al. Atypical hemolytic uremic syndrome and C3 glomerulopathy: conclusions from a "Kidney Disease: Improving Global Outcomes" (KDIGO) controversies conference. Kidney Int. (2017) 91:539-51. doi: 10.1016/j.kint.2016.10.005

13. Ricklin D, Hajishengallis G, Yang K, Lambris JD. Complement: a key system for immune surveillance and homeostasis. Nat Immunol. (2010) 11:785-97. doi: 10.1038/ni.1923

14. Merle NS, Church SE, Fremeaux-Bacchi V, Roumenina LT. Complement system part I - molecular mechanisms of activation and regulation. Front Immunol. (2015) 6:262. doi: 10.3389/fimmu.2015.00262

15. Zipfel PF, Skerka C, Chen Q, Wiech T, Goodship T, Johnson S, et al. The role of complement in C3 glomerulopathy. Mol Immunol. (2015) 67:21-30. doi: 10.1016/j.molimm.2015.03.012

16. Berends ET, Gorham RD Jr., Ruyken M, Soppe JA, Orhan H, Aerts PC, et al. Molecular insights into the surface-specific arrangement of complement C5 convertase enzymes. BMC Biol. (2015) 13:93. doi: 10.1186/s12915-015-0203-8

17. Zipfel PF, Skerka C. Complement regulators and inhibitory proteins. Nat Rev Immunol. (2009) 9:729-40. doi: 10.1038/nri2620

18. Sethi S, Vrana JA, Fervenza FC, Theis JD, Sethi A, Kurtin PJ, et al. Characterization of C3 in C3 glomerulopathy. Nephrol Dial Transplant. (2017) 32:459-65. doi: 10.1093/ndt/gfw290

19. Lesher AM, Nilsson B, Song WC. Properdin in complement activation and tissue injury. Mol Immunol. (2013) 56:191-8. doi: 10.1016/j.molimm.2013.06.002

20. Michels M, Volokhina EB, van de Kar N, van den Heuvel L. The role of properdin in complement-mediated renal diseases: a new player in complement-inhibiting therapy? Pediatr Nephrol. (2018) doi: 10.1007/s00467-018-4042-z. [Epub ahead of print].

21. Fearon DT, Austen KF. Properdin: binding to $\mathrm{C} 3 \mathrm{~b}$ and stabilization of the C3b-dependent C3 convertase. J Exp Med. (1975) 142:856-63. doi: $10.1084 /$ jem.142.4.856

22. Ricklin D, Reis ES, Lambris JD. Complement in disease: a defence system turning offensive. Nat Rev Nephrol. (2016) 12:383-401. doi: $10.1038 /$ nrneph.2016.70 
23. Noris M, Remuzzi G. Overview of complement activation and regulation. Semin Nephrol. (2013) 33:479-92. doi: 10.1016/j.semnephrol.2013.08.001

24. Daha MR, Fearon DT, Austen KF. C3 nephritic factor (C3NeF): stabilization of fluid phase and cell-bound alternative pathway convertase. J Immunol. (1976) 116:1-7.

25. Sethi S, Fervenza FC, Zhang Y, Zand L, Vrana JA, Nasr SH, et al. C3 glomerulonephritis: clinicopathological findings, complement abnormalities, glomerular proteomic profile, treatment, and follow-up. Kidney Int. (2012) 82:465-73. doi: 10.1038/ki.2012.212

26. Schwertz R, Rother U, Anders D, Gretz N, Scharer K, Kirschfink M. Complement analysis in children with idiopathic membranoproliferative glomerulonephritis: a long-term follow-up. Pediatr Allergy Immunol. (2001) 12:166-72. doi: 10.1034/j.1399-3038.2001.012003166.x

27. Zhang Y, Meyer NC, Wang K, Nishimura C, Frees K, Jones M, et al. Causes of alternative pathway dysregulation in dense deposit disease. Clin J Am Soc Nephrol. (2012) 7:265-74. doi: 10.2215/CJN.07900811

28. Weiler JM, Daha MR, Austen KF, Fearon DT. Control of the amplification convertase of complement by the plasma protein beta1H. Proc Natl Acad Sci USA. (1976) 73:3268-72. doi: 10.1073/pnas.73.9.3268

29. Ito S, Tamura N, Fujita T. Effect of decay-accelerating factor on the assembly of the classical and alternative pathway $\mathrm{C} 3$ convertases in the presence of $\mathrm{C} 4$ or C3 nephritic factor. Immunology. (1989) 68:449-52.

30. Ohi H, Watanabe S, Fujita T, Yasugi T. Significance of C3 nephritic factor $(\mathrm{C} 3 \mathrm{NeF})$ in non-hypocomplementaemic serum with membranoproliferative glomerulonephritis (MPGN). Clin Exp Immunol. (1992) 89:479-84. doi: 10.1111/j.1365-2249.1992.tb06984.x

31. Paixao-Cavalcante D, Lopez-Trascasa M, Skattum L, Giclas PC, Goodship TH, de Cordoba SR, et al. Sensitive and specific assays for C3 nephritic factors clarify mechanisms underlying complement dysregulation. Kidney Int. (2012) 82:1084-92. doi: 10.1038/ki.2012.250

32. Daha MR, Kok DJ, Van Es LA. Regulation of the C3 nephritic factor stabilized C3/C5 convertase of complement by purified human erythrocyte C3b receptor. Clin Exp Immunol. (1982) 50:209-14.

33. Tanuma $\mathrm{Y}$, Ohi H, Hatano $\mathrm{M}$. Two types of $\mathrm{C} 3$ nephritic factor: properdindependent $\mathrm{C} 3 \mathrm{NeF}$ and properdin-independent $\mathrm{C} 3 \mathrm{NeF}$. Clin Immunol Immunopathol. (1990) 56:226-38. doi: 10.1016/0090-1229(90)90144-F

34. Clardy CW, Forristal J, Strife CF, West CD. A properdin dependent nephritic factor slowly activating C3, C5, and C9 in membranoproliferative glomerulonephritis, types I and III. Clin Immunol Immunopathol. (1989) 50:333-47. doi: 10.1016/0090-1229(89)90141-4

35. Nester CM, Smith RJ. Complement inhibition in C3 glomerulopathy. Semin Immunol. (2016) 28:241-9. doi: 10.1016/j.smim.2016.06.002

36. Legendre CM, Campistol JM, Feldkamp T, Remuzzi G, Kincaid JF, Lommele A, et al. Outcomes of patients with atypical haemolytic uraemic syndrome with native and transplanted kidneys treated with eculizumab: a pooled post hoc analysis. Transpl Int. (2017) 30:1275-83. doi: 10.1111/tri.13022

37. Le Quintrec M, Lapeyraque AL, Lionet A, Sellier-Leclerc AL, Delmas $\mathrm{Y}$, Baudouin V, et al. Patterns of clinical response to eculizumab in patients with C3 glomerulopathy. Am J Kidney Dis. (2018) 72:84-92. doi: 10.1053/j.ajkd.2017.11.019

38. Mastellos DC, Reis ES, Ricklin D, Smith RJ, Lambris JD. Complement C3-targeted therapy: replacing long-held assertions with evidence-based discovery. Trends Immunol. (2017) 38:383-94. doi: 10.1016/j.it.2017.03.003

39. Ricklin D, Mastellos DC, Reis ES, Lambris JD. The renaissance of complement therapeutics. Nat Rev Nephrol. (2018) 14:26-47. doi: 10.1038/nrneph.2017.156

40. Bekassy ZD, Kristoffersson AC, Rebetz J, Tati R, Olin AI, Karpman D. Aliskiren inhibits renin-mediated complement activation. Kidney Int. (2018) 94:689-700. doi: 10.1016/j.kint.2018.04.004

41. Michels M, van de Kar N, Okroj M, Blom AM, van Kraaij SAW, Volokhina $\mathrm{EB}$, et al. Overactivity of alternative pathway convertases in patients with complement-mediated renal diseases. Front Immunol. (2018) 9:612. doi: 10.3389/fimmu.2018.00612

42. Volokhina EB, Westra D, van der Velden TJ, van de Kar NC, Mollnes TE, van den Heuvel LP. Complement activation patterns in atypical haemolytic uraemic syndrome during acute phase and in remission. Clin Exp Immunol. (2015) 181:306-13. doi: 10.1111/cei.12426

43. Bergseth G, Ludviksen JK, Kirschfink M, Giclas PC, Nilsson B, Mollnes TE. An international serum standard for application in assays to detect human complement activation products. Mol Immunol. (2013) 56:232-9. doi: 10.1016/j.molimm.2013.05.221

44. Siezenga MA, van der Geest RN, Mallat MJ, Rabelink TJ, Daha MR, Berger SP. Urinary properdin excretion is associated with intrarenal complement activation and poor renal function. Nephrol Dial Transplant. (2010) 25:115761. doi: 10.1093/ndt/gfp630

45. Tyson KR, Elkins C, de Silva AM. A novel mechanism of complement inhibition unmasked by a tick salivary protein that binds to properdin. $J$ Immunol. (2008) 180:3964-68. doi: 10.4049/jimmunol.180.6.3964

46. Tyson K, Elkins C, Patterson H, Fikrig E, de Silva A. Biochemical and functional characterization of Salp20, an ixodes scapularis tick salivary protein that inhibits the complement pathway. Insect Mol Biol. (2007) 16:469-79. doi: 10.1111/j.1365-2583.2007.00742.x

47. Linton SM, Morgan BP. Properdin deficiency and meningococcal diseaseidentifying those most at risk. Clin Exp Immunol. (1999) 118:189-91. doi: 10.1046/j.1365-2249.1999.01057.x

48. Fijen $\mathrm{CA}$, van den Bogaard $\mathrm{R}$, Schipper $\mathrm{M}$, Mannens $\mathrm{M}$, Schlesinger M, Nordin FG, et al. Properdin deficiency: molecular basis and disease association. Mol Immunol. (1999) 36:863-67. doi: 10.1016/S0161-5890(99)00107-8

49. Gullipalli D, Zhang F, Sato S, Ueda Y, Kimura Y, Golla M, et al. Antibody inhibition of properdin prevents complement-mediated intravascular and extravascular hemolysis. J Immunol. (2018) 201:1021-9. doi: 10.4049/jimmunol.1800384

50. Pauly D, Nagel BM, Reinders J, Killian T, Wulf M, Ackermann S, et al. A novel antibody against human properdin inhibits the alternative complement system and specifically detects properdin from blood samples. PLoS ONE. (2014) 9:e96371. doi: 10.1371/journal.pone.009 6371

51. Gupta-Bansal R, Parent JB, Brunden KR. Inhibition of complement alternative pathway function with anti-properdin monoclonal antibodies. Mol Immunol. (2000) 37:191-201. doi: 10.1016/S0161-5890(00) 00047-X

52. Blatt AZ, Saggu G, Kulkarni KV, Cortes C, Thurman JM, Ricklin D, et al. Properdin-mediated C5a production enhances stable binding of platelets to granulocytes in human whole blood. J Immunol. (2016) 196:4671-80. doi: 10.4049/jimmunol.1600040

53. Kouser L, Abdul-Aziz M, Tsolaki AG, Singhal D, Schwaeble WJ, Urban BC, et al. A recombinant two-module form of human properdin is an inhibitor of the complement alternative pathway. Mol Immunol. (2016) 73:76-87. doi: 10.1016/j.molimm.2016.03.005

54. Hourcade DE, Akk AM, Mitchell LM, Zhou HF, Hauhart R, Pham CT. Anticomplement activity of the Ixodes scapularis salivary protein Salp20. Mol Immunol. (2016) 69:62-9. doi: 10.1016/j.molimm.2015.11.008

55. Lesher AM, Zhou L, Kimura Y, Sato S, Gullipalli D, Herbert AP, et al. Combination of factor $\mathrm{H}$ mutation and properdin deficiency causes severe C3 glomerulonephritis. J Am Soc Nephrol. (2013) 24:53-65. doi: 10.1681/ASN.2012060570

56. Ruseva MM, Vernon KA, Lesher AM, Schwaeble WJ, Ali YM, Botto M, et al. Loss of properdin exacerbates $\mathrm{C} 3$ glomerulopathy resulting from factor $\mathrm{H}$ deficiency. J Am Soc Nephrol. (2013) 24:43-52. doi: 10.1681/ASN.2012060571

Conflict of Interest Statement: $\mathrm{NvdK}$ is a member of the international aHUS Advisory Board of Alexion.

The remaining authors declare that the research was conducted in the absence of any commercial or financial relationships that could be construed as a potential conflict of interest.

Copyright (C) 2019 Michels, van de Kar, van den Bos, van der Velden, van Kraaij, Sarlea, Gracchi, Oosterveld, Volokhina and van den Heuvel. This is an open-access article distributed under the terms of the Creative Commons Attribution License (CC BY). The use, distribution or reproduction in other forums is permitted, provided the original author(s) and the copyright owner(s) are credited and that the original publication in this journal is cited, in accordance with accepted academic practice. No use, distribution or reproduction is permitted which does not comply with these terms. 